C. Eberle, P. Gerlinger, M. Aigner

Large Eddy Simulations of a Sooting Lifted Turbulent J et-Flame

Proceedings. 55th AIAA Aerospace Sciences Meeting, 08.-13.01.2017, Grapevine, TX, USA.

The AIAA version of the paper is accessible at http://dx.doi.org/10.2514/6.2017-1785

On the AIAA web page http://www.aiaa.org/content.cfm?pageid=2

the interested reader can find other material published by AIAA 


\title{
Large Eddy Simulations of a Sooting Lifted Turbulent Jet-Flame
}

\author{
C. Eberle ${ }^{*}$, P. Gerlinger ${ }^{\dagger}$, M. Aigner $\ddagger$ \\ Institute of Combustion Technology, German Aerospace Center DLR, Stuttgart, 70569, Germany
}

\begin{abstract}
A sooting, turbulent jet flame is investigated numerically by large eddy simulations (LES). The ethylene fueled flame has been characterized experimentally by various nonintrusive high-speed laser diagnostic techniques yielding comprehensive validation data. Combustion is described by finite-rate chemistry with an assumed probability density function (APDF) closure for sub grid scale chemistry-turbulence interaction. The evolution of polycyclic aromatic hydrocarbons (PAHs) is modeled using a recently published sectional model which considers PAH radicals and reversible PAH chemistry. A novel sectional soot model is presented and investigated. This model provides detailed information about the soot morphology by taking into account the evolution of fractal soot aggregates. The model has been validated for laminar diffusion flames where excellent agreement to measurements has been observed. This validated model has then be used for LES of a turbulent jet flame and a very good agreement to measured velocity components, ethylene mole fractions, and soot volume fractions has been found.
\end{abstract}

\section{Introduction}

During the last decades, accurate soot predictions in turbulent combustion have become a pressing technological need, not only due to adverse effects of soot and soot precursors on health, environment and climate ${ }^{1,2,3,4,5,6}$ but also from an engineering point of view. This is because soot has a high radiative emissivity and therefore contributes to locally elevated heat loads on combustion chamber walls. ${ }^{7,8,9}$ Due to the increasing availability of computational resources, computational fluid dynamics (CFD) is a promising tool in the design process of combustion systems. CFD provides detailed, time-resolved information about the three dimensional, reactive flow field and thereby complements experimental investigations which are in many cases limited to exhaust gas analysis, since optical access to the flame is not realizable. Turbulent jet flames are important for the development and validation of soot models for technically relevant combustion systems since the impact of turbulence on soot evolution can be investigated at well defined boundary conditions and simple geometries. While previous LES simulations of sooting jet flames mainly addressed pilot stabilized ${ }^{10,11}$ and bluff-body stabilized flames, ${ }^{12}$ the focus of this work is a lifted flame. ${ }^{13}$ This is because flames in technical combustion devices are lifted in many cases. As the prediction of the lift-off height is challenging, a finite-rate combustion model, which provides a detailed description of chemical kinetics, is used. Comprehensive validation data, including measurements of temperature, concentrations of ethylene and polycyclic aromatic hydrocarbons (PAHs) as well as simultaneous measurements of the velocity field and the soot volume fraction are available for the chosen test case. ${ }^{13,14,15}$

Previous Reynolds averaged Navier-Stokes simulations (RANS) of this flame ${ }^{13,16}$ showed a reasonable overall agreement between simulation and experiment. ${ }^{13}$ These simulations however revealed the limitations of RANS to accurately predict turbulent mixing phenomena as deviations between predicted and measured soot volume fractions could partially be attributed to inaccurate predictions of turbulent mixing. Therefore, large-eddy simulations (LES) are performed in the present work. The LES approach provides a rigorous treatment of turbulent mixing phenomena by resolving turbulent scales. Another discrepancy between simulation and experiment was that the previously published RANS simulation ${ }^{13,16}$ predicted an too early

*PhD student, DLR - VT, Pfaffenwaldring 38-40, 70569 Stuttgart, Germany

${ }^{\dagger}$ Professor, Institute of Combustion Technology for Aerospace Engineering, Universität Stuttgart, Germany

‡Professor, DLR - VT, Pfaffenwaldring 38-40, 70569 Stuttgart, Germany 
onset of soot formation. Furthermore, soot was oxidized too fast. These deviations can be explained by the simplified treatment of soot precursor chemistry and by the assumption of spherical soot particles. Therefore, the evolution of polycyclic aromatic hydrocarbons (PAHs) is modeled using an improved sectional model ${ }^{17}$ which considers PAH radicals and reversible PAH chemistry. Moreover, a novel sectional soot model is presented and investigated. This model provides detailed information about the soot morphology by taking into account the evolution of fractal soot aggregates. The model has been validated for laminar diffusion flames where excellent agreement to measurements has been observed. All simulations use the DLR in-house code THETA (turbulent heat release extension of the TAU code).

\section{Methodology}

\section{II.A. Governing Equations of Turbulent Combustion}

The filtered and modeled equations for conservation of mass and momentum read:

$$
\begin{gathered}
\frac{\partial \bar{\rho}}{\partial t}+\frac{\partial \bar{\rho} \widetilde{u}_{i}}{\partial x_{i}}=0 \\
\frac{\partial \bar{\rho} \widetilde{u}_{i}}{\partial t}+\frac{\partial \bar{\rho} \widetilde{u}_{i} \widetilde{u}_{j}}{\partial x_{j}}+\frac{\partial \overline{p^{*}}}{\partial x_{i}}-2 \frac{\partial}{\partial x_{j}}\left(\left(\mu+\mu_{t}\right)\left(\widetilde{S}_{i, j}-\frac{1}{3} \widetilde{S}_{k, k} \delta_{i, j}\right)\right)=\bar{\rho} g_{i},
\end{gathered}
$$

where the overbars $\bar{\phi}$ and $\widetilde{\phi}$ denote Reynolds and Favre filtering. The Einstein summation convention is applied here and in the following. $u_{i}$ is the velocity component in $x_{i}$-direction, $\rho$ the density, $\mu$ the molecular viscosity, $\mu_{t}$ the turbulent viscosity, $S_{i, j}$ the strain tensor and $g_{i}$ the gravity constant in $x_{i}$-direction. The pseudo-pressure $p^{*}$ is defined as $p^{*}=p+\frac{2}{3} \rho k \delta_{i j}$, where $p$ is the pressure, $k$ the turbulent kinetic energy and $\delta_{i j}$ the Kronecker delta. Sub-grid scale fluctuations are modelled by the wall adaptive local eddy viscosity model (WALE). ${ }^{18}$ The filtered and modeled transport equations of specific enthalpy $h$ ( $h$ is defined as the sum of thermal and chemical enthalpy: $h=\int_{T_{0}}^{T} c_{p} \mathrm{~d} T+\sum_{\alpha} \Delta h_{f, \alpha}^{0}$, where $\Delta h_{f, \alpha}^{0}$ is the standard enthalpy of formation) and reactive scalars $Y_{\alpha}$ (including mass fractions of gaseous species, PAHs and soot sections.) read:

$$
\begin{gathered}
\frac{\partial \bar{\rho} \widetilde{h}}{\partial t}+\frac{\partial \bar{\rho} \tilde{u}_{i} \widetilde{h}}{\partial x_{i}}-\frac{\partial}{\partial x_{i}}\left(\left(\frac{\lambda}{c_{p}}+\frac{\mu_{t}}{\operatorname{Pr}_{t}}\right) \frac{\partial \widetilde{h}}{\partial x_{i}}\right)=\widetilde{\omega}_{h}, \\
\frac{\partial \bar{\rho} \widetilde{Y}_{\alpha}}{\partial t}+\frac{\partial \bar{\rho} \tilde{u}_{i} \widetilde{Y}_{\alpha}}{\partial x_{i}}-\frac{\partial}{\partial x_{i}}\left(\left(\frac{\mu}{\mathrm{Sc}}+\frac{\mu_{t}}{\mathrm{Sc}_{t}}\right) \frac{\partial \widetilde{Y}_{\alpha}}{\partial x_{i}}\right)=\widetilde{\omega}_{\alpha},
\end{gathered}
$$

where $\lambda$ is the thermal conductivity, $c_{p}$ the specific heat at constant pressure, $\operatorname{Pr}_{t}=0.7$ the turbulent Prandtl number, and $\mathrm{Sc}$ and $\mathrm{Sc}_{t}=0.7$ the laminar and turbulent Schmidt number, respectively. Soot particles do not engage in molecular diffusion. This is modelled by a infinitely large Schmidt number $(1 / \mathrm{Sc}=0)$ for soot sections. For other reactive scalars $\mathrm{Sc}=0.7$ is assumed. The source terms $\omega_{h}$ and $\omega_{\alpha}$ describe heat radiation and consumption as well as production of reactive species due to chemical reactions, respectively.

\section{II.B. Heat Radiation}

Assuming an optically thin medium, the heat radiation source term reads:

$$
\omega_{h}=-4 \sigma_{S} \rho T^{4} \sum_{\alpha_{\mathrm{rad}}} \epsilon_{\alpha_{\mathrm{rad}}}(T) Y_{\alpha_{\mathrm{rad}}}
$$


where $\sigma_{S}$ is the Stefan-Boltzmann constant and the index $\alpha_{\text {rad }}$ denotes the heat radiating species (soot, $\mathrm{CO}_{2}$, and $\mathrm{H}_{2} \mathrm{O}$ ) The emissivity coefficients are derived from the work of Mauss ${ }^{19}$ and read:

$$
\begin{aligned}
\epsilon_{\mathrm{CO}_{2}} & =\frac{46.241 \frac{1}{m} \mathcal{R}}{p_{0} M_{\mathrm{CO}_{2}}} \exp \left(-8.888 \times 10^{-4} T\right) T, \\
\epsilon_{\mathrm{H}_{2} \mathrm{O}} & =\frac{22.6 \frac{1}{m} \mathcal{R}}{p_{0} M_{\mathrm{H}_{2} \mathrm{O}}} \exp \left(-1.546 \times 10^{-3} T\right) T, \\
\epsilon_{s} & =\frac{-3.75 \times 10^{5}}{\rho_{s}}+\frac{1735}{\rho_{s}} T .
\end{aligned}
$$

Because of disparate time scales of soot and thermo-chemical variables, statistical independence of soot mass fraction and temperature can be assumed, ${ }^{20}$ leading to

$$
\widetilde{\omega}_{h}=-\frac{4 \sigma_{S} p}{R} \sum_{\alpha_{\mathrm{rad}}}\left(\widetilde{Y}_{\alpha_{\mathrm{rad}}} \int \epsilon_{\alpha_{\mathrm{rad}}}(\hat{T}) \hat{T}^{3} P(\hat{T}) \mathrm{d} \hat{T}\right)
$$

for the filtered heat radiation source term, where $P(\hat{T})$ is a clipped Gaussian PDF. The radiation model was validated in previous work.$^{13,21,22}$

\section{II.C. Chemical Source Term}

The chemical source term $\omega_{\alpha}$ is described by a finite-rate combustion model where a separate transport equation is solved for each reactive scalar $\alpha$. With the general form of a chemical reaction $r$,

$$
\sum_{\alpha=1}^{N_{s p}} \nu_{\alpha, r}^{\prime} \alpha=\sum_{\alpha=1}^{N_{s p}} \nu_{\alpha, r}^{\prime \prime} \alpha
$$

where $\nu$ are stoichiometric coefficients and $N_{s p}$ the number of species, the compact notation of the chemical source term $\omega_{\alpha}$ is written as:

$$
\omega_{\alpha}=M_{\alpha} \sum_{r=1}^{N_{r}}\left\{\left(\nu_{\alpha, r}^{\prime \prime}-\nu_{\alpha, r}^{\prime}\right)\left(k_{f, r} \prod_{\beta=1}^{N_{s p}} C_{\beta}^{O_{\beta, r}^{\prime}}-k_{b, r} \prod_{\beta=1}^{N_{s p}} C_{\beta}^{O_{\beta, r}^{\prime \prime}}\right)\right\} .
$$

$M_{\alpha}$ is the molar mass of species $\alpha, N_{r}$ the number of reactions, and $O$ the reaction order, respectively. $C_{\beta}=\rho Y_{\beta} / M_{\beta}$ is the concentration of species $\beta . \quad k_{f}$ and $k_{b}$ are forward and backward rate coefficients which are modeled by Arrhenius equations. All chemical reactions involving soot and PAHs are formulated in Arrhenius form and are thus compatible to chemical reactions of gas phase species. ${ }^{21,22}$ Hence, the transport equations stemming from the $\mathrm{PAH}$ and soot models are solved by the finite-rate chemistry solver in the same way as the transport equations of gas phase species, thereby allowing a full coupling between soot, PAHs and the thermo-chemical state of the gas phase. Feedback effects of soot and PAHs on the gas phase such as consumption of gaseous soot precursors (predominantly acetylene, benzene and toluene) as well as heat radiation are thus inherently captured accurately.

The chemical source term is filtered using an assumed probability density function approach (APDF). ${ }^{23,24}$ Assuming statistical independence of temperature and species fluctuations, the filtered chemical source term reads:

$$
\widetilde{\omega}_{\alpha}=\iint \omega_{\alpha}(\hat{T}, \hat{\boldsymbol{Y}}) P(\hat{T}) P(\hat{\boldsymbol{Y}}) \mathrm{d} \hat{T} \mathrm{~d} \hat{\boldsymbol{Y}}
$$

where $P(\hat{T})$ is a clipped Gaussian PDF and $P(\hat{\boldsymbol{Y}})$ a multivariate $\beta$-PDF. ${ }^{23}$ The PDFs are parameterized by first-order moments and two second-order moments $\left(P(\hat{T})\right.$ by the temperature variance $\sigma_{T}$ and $P(\hat{\boldsymbol{Y}})$ by the sum of species variances $\left.\sigma_{Y}=\sum_{\alpha} \widetilde{Y_{\alpha}^{\prime \prime 2}}\right)$. As an analytical integration of $P(\hat{\boldsymbol{Y}})$ is only possible for elementary reactions, the concentration products of global reactions are directly evaluated on the filtered variables. Our implementation of the APDF model was validated by Di Domenico ${ }^{25}$ who simulated well characterized turbulent flames from the TNF workshop and in a later work ${ }^{26}$ confined, turbulent, premixed flames. Köhler et al. ${ }^{13}$ recently used the APDF approach for simulations of a turbulent sooting jet flame and observed good agreement between measured and calculated temperature and $\mathrm{OH}$ distribution. Other recent simulations of complex combustion configurations ${ }^{27,28,29,30}$ further demonstrate the applicability of the APDF approach. 


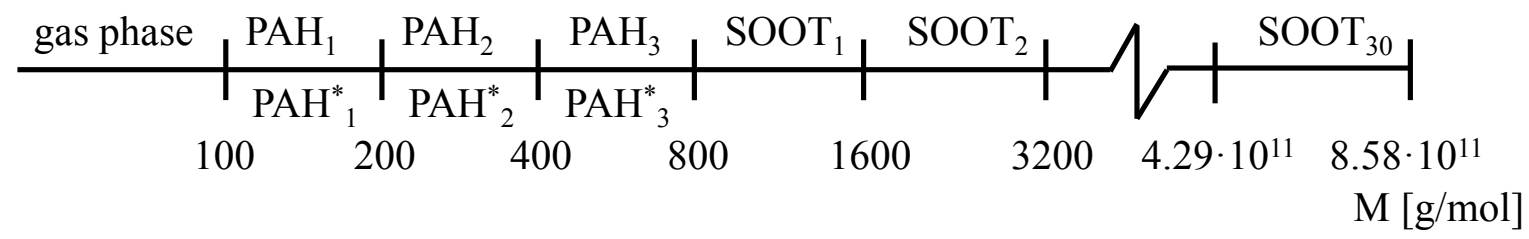

Figure 1. Definition of the $\mathrm{PAH}, \mathrm{PAH}^{*}$, and soot sections.

\section{II.D. Gas Phase Chemistry}

The kinetics of gas phase species are modeled by a reaction mechanism which describes the formation of hydrocarbons up to benzene and toluene. The mechanism includes 43 species and 304 elementary reactions and has been validated for pyrolysis and combustion of small hydrocarbons, such as methane or ethylene at atmospheric and high-pressure conditions.${ }^{31}$ This mechanism has been obtained by reduction of the detailed mechanism of Slavinskaya et al. ${ }^{32}$ and has successfully been used for soot predictions in previous works. ${ }^{29,22,13}$

\section{II.E. PAH Model}

As shown in Fig. 1, PAHs are described by three logarithmically scaled sections. The minimum PAH mass is set to $100 \mathrm{~g} / \mathrm{mol}$ in order to cover all PAHs (Naphthalene being the smallest PAH has a molar mass of $128 \mathrm{~g} / \mathrm{mol}$ ). As the maximum PAH mass is assumed to be equal to the minimum soot mass (cf. Fig. 1), the maximum PAH mass has to be chosen in a way to yield incipient soot particles of realistic size. At the same time the maximum PAH mass should be as small as possible. This is because modelling uncertainties may increase with increasing PAH size since, as will be shown in the following, chemical analogy to small PAHs is assumed. In this context, it was decided to set the maximum PAH mass to $800 \mathrm{~g} / \mathrm{mol}$ leading to an incipient soot particle diameter of $1.28 \mathrm{~nm}$ which is in line with measured particle diameters. ${ }^{33}$ To describe reversible $\mathrm{PAH}$ chemistry, a radical branch $\mathrm{PAH}_{i}^{*}$ is assigned to each $\mathrm{PAH}$ section.

$\mathrm{PAH}$ chemistry is divided into four processes: $\mathrm{PAH}_{1}$ gas phase interaction, $\mathrm{PAH}$ dehydrogenation, acetylene $\left(\mathrm{C}_{2} \mathrm{H}_{2}\right)$ addition, and $\mathrm{PAH}$ oxidation. The chemical kinetics describing these processes are defined in analogy to small PAHs. Rate parameters are taken from a detailed reaction mechanism which describes the kinetics of PAHs up to benzo(a)pyrene. ${ }^{34} \mathrm{PAH}_{1}$ gas phase interaction describes the formation and consumption of $\mathrm{PAH}_{1}$ and $\mathrm{PAH}_{1}^{*}$ by reactions with chemical species included in the gas phase mechanism (for instance benzene or toluene). This is described by 25 reversible reactions for $\mathrm{PAH}_{1}$ gas phase interaction. An example is the reaction $\mathrm{C}_{7} \mathrm{H}_{7}+\mathrm{CH}_{2}=\mathrm{A}_{1} \mathrm{C}_{2} \mathrm{H}_{3}+\mathrm{H}$, where styrene is replaced by $(\nu \mathrm{PAH} 0)$ and the stoichiometric coefficient $\nu$ is calculated from conservation of mass. These reactions are taken from the work of Slavinskaya et al. ${ }^{34}$ The full $\mathrm{PAH}_{1}$ gas phase interaction mechanism is given in previous work. ${ }^{17}$ Dehydrogenation or $\mathrm{H}$-atom abstraction is the first step of the hydrogen-abstraction acetylene-addition (HACA) mechanism. ${ }^{35}$ In the present approach, dehydrogenation of PAHs by H-atoms, O-atoms, hydroxyl $(\mathrm{OH})$, and unimolecular decomposition is considered:

$$
\begin{aligned}
\mathrm{PAH}_{i}+\mathrm{OH} & =\mathrm{PAH}_{i}^{*}+\mathrm{H}_{2} \mathrm{O} \\
\mathrm{PAH}_{i}+\mathrm{H} & =\mathrm{PAH}_{i}^{*}+\mathrm{H}_{2} \\
\mathrm{PAH}_{i}+\mathrm{O} & =\mathrm{PAH}_{i}^{*}+\mathrm{OH} \\
\mathrm{PAH}_{i}^{*}+\mathrm{H} & =\mathrm{PAH}_{i}
\end{aligned}
$$

The second step of the HACA mechanism is $\mathrm{C}_{2} \mathrm{H}_{2}$ addition at a reactive site of a PAH radical:

$$
\begin{aligned}
\mathrm{PAH}_{j}^{*}+\mathrm{C}_{2} \mathrm{H}_{2} & \rightarrow \nu_{1} \mathrm{PAH}_{j}+\nu_{2} \mathrm{PAH}_{j+1}+\nu_{3} \mathrm{H}, \\
\mathrm{PAH}_{j}+\mathrm{H} & \rightarrow \nu_{1} \mathrm{PAH}_{j-1}^{*}+\nu_{2} \mathrm{PAH}_{j}^{*}+\nu_{3} \mathrm{H}_{2}+\mathrm{C}_{2} \mathrm{H}_{2} .
\end{aligned}
$$

Following Pope an Howard, ${ }^{36}$ the stoichiometric coefficients $\nu_{i}$ are calculated depending on intra sectional distribution functions and atom conservation. This is done in a way that both, mass and atoms are conserved (more details are given in previous works ${ }^{22,17}$ ). This procedure is also applied in case of PAH oxidation and $\mathrm{PAH}$ collisions. The reaction rate parameters for the $\mathrm{C}_{2} \mathrm{H}_{2}$ addition are obtained by assuming chemical 
analogy to the pyrene radical. ${ }^{34}$ In case of $\mathrm{C}_{2} \mathrm{H}_{2}$ addition to the last PAH section $\left(j=3\right.$ in Eq. (17), $\nu_{2}$ is set to zero and in this case Eq. (17) reads $\mathrm{PAH}_{3}^{*}+\mathrm{C}_{2} \mathrm{H}_{2} \rightarrow \nu_{1} \mathrm{PAH}_{3}+\nu_{3} \mathrm{H}$. The collision source term is given in general form by

$$
\omega_{i, j}=2.2 \gamma_{i, j} \beta_{i, j}\left[\mathrm{BIN}_{i}\right]\left[\mathrm{BIN}_{j}\right]
$$

where 2.2 is the van der Waals enhancement factor and $\mathrm{BIN}_{i}$ is a place holder for either $\mathrm{PAH}_{i}, \mathrm{PAH}_{i}^{*}$ or $\operatorname{SOOT}_{i}$. The collision frequency $\beta_{i, j}$ is calculated using a formulation which applies for the entire Knudsen number range. ${ }^{2,37}$ As will be discussed in the following, different efficiencies $\gamma_{i, j}$ are used depending on the type of collision process. Concerning PAH collisions, it is distinguished between a molecular growth mechanism (where radical sites are required for reaction) and coagulation processes based on collision frequencies from the kinetic theory of gases. The latter do not require radical sites, however low molecular mass compounds have low collision efficiencies. ${ }^{38}$ Using a correlation developed by Saggese et al., ${ }^{39}$ efficiencies in the order of $10^{-3}$ were obtained for collisions involving $\mathrm{PAH}_{3}$. Due to these low efficiencies, it was decided to consider PAH coagulation to be negligibly slow. This assumption has also been taken by Richter et al. ${ }^{40}$ and by Slavinskaya and Frank. ${ }^{32}$ PAH coagulation is however taken into account by some PAH models ${ }^{39,41}$ where PAH molecules larger then those in the present work are considered. Collisions between PAH radicals and collisions between PAH radicals and PAH molecules read for $i, j \in[1,3]$ and $k=\max (i, j)$ in global reaction formulation:

$$
\begin{aligned}
& \mathrm{PAH}_{i}^{*}+\mathrm{PAH}_{j}^{*} \rightarrow \nu_{1} \mathrm{PAH}_{k}+\nu_{2} \mathrm{PAH}_{k+1}+\nu_{3} \mathrm{H}_{2}, \\
& \mathrm{PAH}_{i}^{*}+\mathrm{PAH}_{j} \rightarrow \nu_{1} \mathrm{PAH}_{k}+\nu_{2} \mathrm{PAH}_{k+1}+\nu_{3} \mathrm{H}_{2}+\mathrm{H} .
\end{aligned}
$$

As in, ${ }^{42} \gamma_{i, j}=1$ is assumed. The products of reactions (20) and (21) are PAH molecules and molecular hydrogen is added on the product side to enable atom conservation at a size-dependent $\mathrm{H} / \mathrm{C}$ ratio. The $\mathrm{H}$-atom in reaction (21) ensures conservation of reactive sites. Stoichiometric coefficients are calculated in a way that both, mass and atoms are conserved. Soot nucleation is modeled as a special case of reactions (20) and (21), namely by collisions involving $\mathrm{PAH}_{3}$ or $\mathrm{PAH}_{3}^{*}$ as reactant. In these cases $\mathrm{PAH}_{j+1}$ is replaced by $\mathrm{SOOT}_{1}$ and the reactions read for $1 \leq i \leq 3$

$$
\begin{aligned}
& \mathrm{PAH}_{i}^{*}+\mathrm{PAH}_{3}^{*} \rightarrow \nu_{1} \mathrm{PAH}_{3}+\nu_{2} \mathrm{SOOT}_{1}+\nu_{3} \mathrm{H}_{2} \\
& \mathrm{PAH}_{i}^{*}+\mathrm{PAH}_{3} \rightarrow \nu_{1} \mathrm{PAH}_{3}+\nu_{2} \mathrm{SOOT}_{1}+\nu_{3} \mathrm{H}_{2}+\mathrm{H}
\end{aligned}
$$

The condensation of $\mathrm{PAH}_{i}$ or $\mathrm{PAH}_{i}^{*}$ onto soot particles is given by

$$
\begin{aligned}
& \mathrm{PAH}_{i}+\mathrm{SOOT}_{j} \rightarrow \nu_{1} \mathrm{SOOT}_{j}+\nu_{2} \mathrm{SOOT}_{j+1}+\nu_{3} \mathrm{H}_{2}, \\
& \mathrm{PAH}_{i}^{*}+\mathrm{SOOT}_{j} \rightarrow \nu_{1} \mathrm{SOOT}_{j}+\nu_{2} \mathrm{SOOT}_{j+1}+\nu_{3} \mathrm{H}_{2}+\mathrm{H},
\end{aligned}
$$

where $1 \leq i \leq 3$ and $1 \leq j \leq 24$. Based on previous studies, ${ }^{22} \gamma_{i, j}=0.3$ is used for PAH condensation.

\section{II.F. Soot Model}

\section{II.F.1. Thermodynamic Properties of Soot}

In this work, the thermodynamic properties of soot are determined using the methodology developed by Blacha et al., ${ }^{22}$ which is briefly summarized here. A constant soot density of $\rho_{s}=1800 \mathrm{~kg} / \mathrm{m}^{343,40}$ is assumed. The hydrogen to carbon $(\mathrm{H} / \mathrm{C})$ ratio of soot decreases with increasing particle mass. In this work the correlation of Blacha et al. ${ }^{22}$

$$
\mathrm{H} / \mathrm{C}=0.4405 M^{-0.10524}
$$

is used which is based on data from Richter et al. ${ }^{40}$

\section{II.F.2. Description of the soot morphology}

In the present work, the soot size distribution is described by a sectional approach. In sectional approaches, the number of soot sections is governed by the minimum and the maximum soot mass, and by the scaling factor between the masses of subsequent sections

$$
x_{M}=M_{i+i} / M_{i}
$$


Corresponding to the geometric constraint of Gelbard and Seinfeld ${ }^{44}\left(x_{M} \geq 2\right), x_{M}=2$ has been chosen. While the minimum soot mass is equal to the maximum PAH mass (see section II.E and Fig. 1), the maximum soot mass must be chosen large enough to fully resolve the particle size distribution. The number of soot sections required to resolve the PSD depends thus on the test case. In the present work, 30 sections have been chosen, which has been found to be sufficient even for the heavily sooting diffusion flames considered in this work. A soot section represents a mono disperse soot aggregat (all primary particles within one aggregat have the same diameter) with an average molar mass $M_{i}$, a number of primary particles per aggregate $n_{p, i}$ and a primary particle diameter $d_{p, i}$ which is given by

$$
d_{p, i}=\sqrt[3]{\frac{6 M_{i}}{N_{a} \pi \rho_{s} n_{p, i}}}
$$

With the definition of the aggregation factor $\chi_{\mathrm{agg}} \in\left[1, x_{M}\right]$ the properties of section $i+1$ are given as a function of the known properties of section $i$

$$
\begin{aligned}
d_{p, i+1} & =\sqrt[3]{\frac{x_{M}}{\chi_{\mathrm{agg}}}} d_{p, i} \\
n_{p, i+1} & =\chi_{\mathrm{agg}} n_{p, i}
\end{aligned}
$$

The boundary values $\chi_{\mathrm{agg}}=1$ and $\chi_{\text {agg }}=x_{M}$ represent purely coalescent growth $\left(n_{p, i}=\right.$ const.) and pure aggregate formation $\left(d_{p, i}=\right.$ const.) while $1<\chi_{\text {agg }}<x_{M}$ is a super position of both processes. The transition from primary soot particles to soot aggregates is defined by a critical diameter $d_{\text {crit }}$ where aggregates formation starts at $d_{p, i} \geq d_{\text {crit }}$. In this work, $d_{\text {crit }}=14 \mathrm{~nm}$ has been chosen. This is line to literature values which are in the range of $10 \mathrm{~nm}$ to $40 \mathrm{~nm} \cdot{ }^{39,45,46,47}$ The influence of $\chi_{\text {agg }}$ on primary particle diameters and soot surface ratios (surface of a fractal soot aggregate divided by the surface of a spherical particle with equal mass) is shown in Fig 2. The assumption of spherical soot particles leads to unphysically large particles with diameters exceeding $200 \mathrm{~nm}$. In case of $\chi_{\text {agg }}=2.0$ no particles with $d_{p, i}>$ $d_{\text {crit }}$ can exist. By using a value of $\chi_{\text {agg }}=1.5$, realistic primary particle diameters are obtained, however. In particular for large soot sections, $\chi$ agg has a strong influence on the soot surface $\left(n_{p, i} \pi d_{p, i}^{2}\right)$ as the surface of a fractal soot aggregate can be one order of magnitude larger than the surface of a spherical soot particle with the same mass. As will be discussed in the subsequent section, reaction rates of soot surface chemistry scale with the soot surface. Soot surface growth by $\mathrm{C}_{2} \mathrm{H}_{2}$ addition and soot oxidation are thus directly influenced by $\chi_{\text {agg }}$ and careful model validation is required. It will be shown in section III, that using $d_{\text {crit }}=14 \mathrm{~nm}$ and subsequent aggregat formation with $\chi_{\text {agg }}=1.5$ leads to very good predictions of the soot morphology in a series of laminar diffusion flames. In particular, significant improvements compared to $\chi_{\text {agg }}=1$ and $\chi_{\text {agg }}=x_{M}$ simulations have been obtained.

Due to their chain-like structure, the collision properties of soot aggregates differ from those of spherical
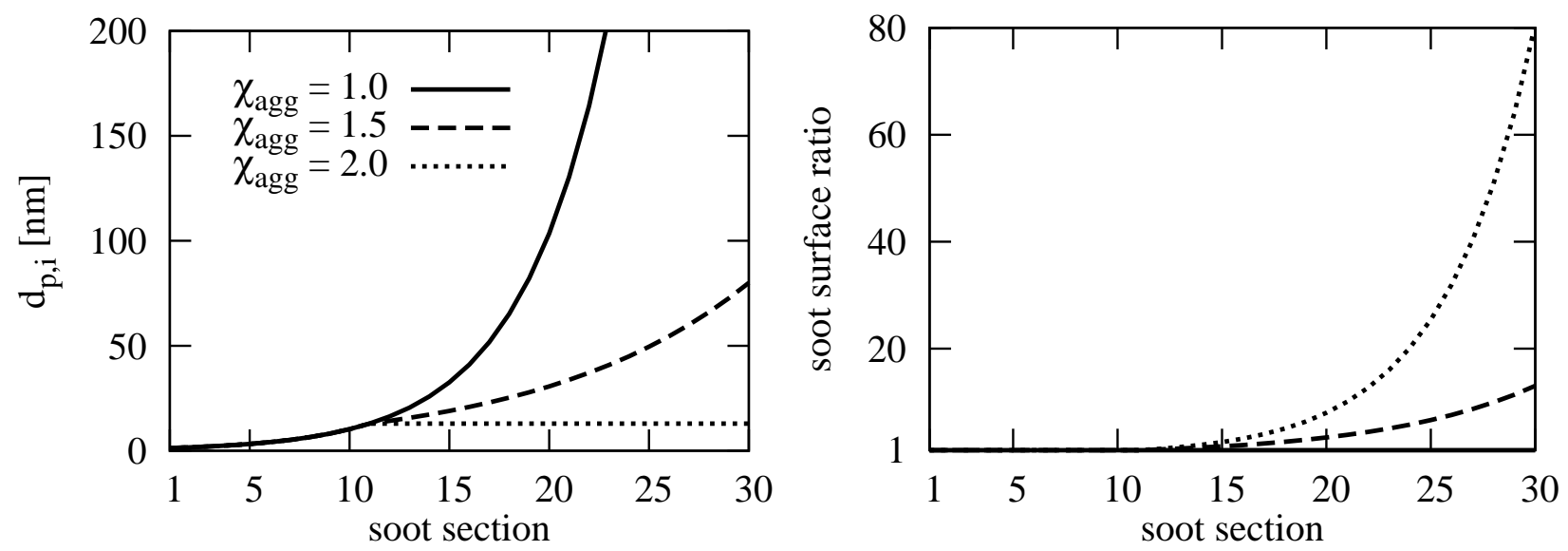

Figure 2. Primary particle diameters $d_{p, i}$ and soot surface ratios (surface of the corresponding fractal soot aggregate divided by the surface of a spherical particle with equal mass). 
Table 1. Per-site coefficients of soot surface chemistry from the work of Appel et al. ${ }^{50}$ Reaction rates are in Arrhenius form: $k=k_{0} T^{\alpha} \exp \left(-T / T_{a}\right)$. Units are mol, $\mathbf{c m}, \mathbf{s}$, and $\mathbf{K}$.

\begin{tabular}{rlccrr}
\hline Soot surface chemistry & $k_{0}$ & $\alpha$ & $T_{a}$ \\
\hline $\mathrm{SOOT}+\mathrm{C}_{2} \mathrm{H}_{2}$ & $\rightarrow$ & products & $8.0 \mathrm{E}+7$ & 1.56 & 1912 \\
$\mathrm{SOOT}+\mathrm{O}_{2}$ & $\rightarrow$ & products & $2.2 \mathrm{E}+12$ & 0 & 3774 \\
\hline
\end{tabular}

particles with equal mass. The morphology of soot aggregates is in statistical average given by ${ }^{48}$

$$
n_{p, i}=k_{g}\left(\frac{2 R_{\mathrm{gyr}, \mathrm{i}}}{d_{p, i}}\right)^{D_{f}}
$$

Assuming the collision diameter $d_{c, i}$ to be equal to the outer aggregat diameter, $d_{c, i}$ is given as a function of the radius of gyration $R_{\mathrm{gyr}, \mathrm{i}}$ (which is known from Eq. (31)) by ${ }^{48}$

$$
d_{c, i}=\sqrt{\frac{D_{f}+2}{D_{f}}} 2 R_{\mathrm{gyr}, \mathrm{i}}
$$

Depending on the fractal dimension $D_{f}$, Eq. (32) applies for different aggregat shapes (for instance $D_{f}=1$ for chains, $D_{f}=2$ for disks and $D_{f}=3$ for spheres $\left.{ }^{48}\right)$. Universal values for the fractal dimension $\left(D_{f}=\right.$ $1.7 \pm 0.15)$ and the fractal prefactor $\left(k_{g}=2.4 \pm 0.4\right)$ of soot aggregates with $24 \mathrm{~nm} \leq d_{p, i} \leq 52 \mathrm{~nm}$ and $2 \leq n_{p, i} \leq 10^{4}$ were obtained by measurements from Kölyü et al. ${ }^{48}$ In this work, $D_{f}$ and $k_{g}$ are calculated using a interpolation scheme developed by Rosner und Pyykönen ${ }^{49}$ which correctly describes the asymptotic behaviour of $D_{f}$ and $k_{g}$ for $n_{p, i} \rightarrow 1$.

\section{II.F.3. Soot Surface Chemistry}

Chemical processes on the soot surface are PAH condensation (which has been discussed in section II.E), $\mathrm{C}_{2} \mathrm{H}_{2}$ addition and oxidation by $\mathrm{O}_{2}$ and $\mathrm{OH}$. Acetylene addition and oxidation by molecular oxygen are complex chemical processes which require active surface sites. The source terms of these reactions read

$$
\begin{aligned}
\omega_{\mathrm{C}_{2} \mathrm{H}_{2}, i} & =k_{\mathrm{C}_{2} \mathrm{H}_{2}} \alpha \chi^{*} n_{p, i} \pi d_{p, i}^{2} \quad\left[\mathrm{SOOT}_{i}\right]\left[\mathrm{C}_{2} \mathrm{H}_{2}\right] \\
\omega_{\mathrm{O}_{2} \text { ox., } \mathrm{i}} & =k_{\mathrm{O}_{2}} \alpha \chi^{*} n_{p, i} \pi d_{p, i}^{2}\left[\mathrm{SOOT}_{i}\right]\left[\mathrm{O}_{2}\right]
\end{aligned}
$$

where $k_{\mathrm{C}_{2} \mathrm{H}_{2}}$ and $k_{\mathrm{O}_{2}}$ are per-site rate coefficients which are defined in analogy to small aromatics. In this work the rate coefficients proposed by Appel et al. ${ }^{50}$ are used (see table 1). The number density of reactive surface sites $\chi^{*}$ is modeled as

$$
\chi^{*}=r_{\chi} \chi_{\mathrm{C}-\mathrm{H}}
$$

where $\chi_{\mathrm{C}-\mathrm{H}}$ is the number density of arm-chair sites. Frenklach and Wang ${ }^{51}$ argued that there is one arm chair site per $1.23 \times 3.51 \AA^{2}(1.23 \AA$ is the half width of a aromatic ring and $3.51 \AA$ the distance of two PAH layers in soot). This results in $\chi_{\mathrm{C}-\mathrm{H}}=2.32 \times 10^{19} \mathrm{~m}^{-2}$. Following the work of Frenklach and Wang, ${ }^{51} r_{\chi}$ is often estimated by quasi steady state expressions. In later works however it was observed this can introduce high modeling uncertainties. ${ }^{52,53}$ Therefore, as in other soot models for turbulent combustion, ${ }^{22,10}$ a constant $r_{\chi}$ is used in this work. By calibration, $r_{\chi}=2.5 \times 10^{-3}$ was obtained, which is in line with typical values $10^{-4} \leq r_{\chi} \leq 10^{-2} \cdot{ }^{54,55}$

As the reactivity of the soot surface may differ from the reactivity of small aromatics, a parameter $\alpha$ has been introduced ${ }^{51}$ to describe the ratio of surface sites which are available for chemical reaction. Since it was not possible to derive a universal constant for $\alpha,{ }^{51}$ functional forms have been developed where $\alpha$ is a function of the temperature ${ }^{56}$ or the first size moment of the soot particle size distribution. ${ }^{50}$ In recent works, the aging of the soot surface was described by correlating $\alpha$ to a thermal age $\mathrm{T}_{\alpha},{ }^{57}$ which has been calculated by Lagrangian scheme. In this work, $\alpha$ is modelled by

$$
\alpha(T)=\left(\frac{1800 K}{T}\right)^{40} \exp \left\{40\left(1-\frac{1800 K}{T}\right)\right\}
$$


Table 2. Boundary conditions of the laminar atmospheric diffusion flames considered in this work

\begin{tabular}{ccc}
\hline Case & $u_{\mathrm{C}_{2} \mathrm{H}_{4}}$ & $u_{\text {co-flow }}$ \\
\hline Flame 2 & $3.98 \mathrm{~cm} / \mathrm{s}$ & $8.9 \mathrm{~cm} / \mathrm{s}$ \\
Flame 4 & $5.05 \mathrm{~cm} / \mathrm{s}$ & $13.3 \mathrm{~cm} / \mathrm{s}$ \\
\hline
\end{tabular}

This function has range of values $0<\alpha \leq 1$ and a global maximum at $\alpha(1800 K)=1$. The decrease of $\alpha$ towards low temperatures models a decreasing radical concentration and thus a lower $r_{\chi}$. The decrease of $\alpha$ towards higher temperature takes into account the graphitization of the soot surface. ${ }^{57}$

As the $\mathrm{OH}$ radical is highly reactive, soot oxidation by $\mathrm{OH}$ does not require reactive sites and is modeled by the kinetic theory assuming the activation energy to be negligibly small

$$
\omega_{\mathrm{OH}-\mathrm{ox}}=\gamma_{\mathrm{OH}-\mathrm{ox}} \underbrace{n_{p, i} N_{a} \sigma_{\mathrm{OH}-\mathrm{ox}} \sqrt{\frac{8 k_{B} T}{\pi \mu_{\mathrm{OH}-\mathrm{ox}}}}}_{\beta_{\mathrm{OH}-\mathrm{ox}}} \underbrace{\exp \left\{\frac{T_{a}}{T}\right\}}_{\approx 1\left(T_{a} \approx 0\right)}\left[\mathrm{SOOT}_{i}\right][\mathrm{OH}]
$$

Many works follow Neoh et al. ${ }^{58}$ who proposed a constant collision efficiency $\gamma_{\mathrm{OH}-\mathrm{ox}}=0.13$. In a later work, Haudiquert et al. ${ }^{59}$ performed measurements in a high temperature ethylene flame and found a decreasing efficiency for high temperatures $(\mathrm{T}>2000 \mathrm{~K})$. Liu et al. ${ }^{60}$ used $\gamma_{\mathrm{OH}-\mathrm{ox}}=0.2$ multiplied by an empirical function with lead to a decreasing $\gamma_{\mathrm{OH}-\mathrm{ox}}$ towards low temperatures. This was found to be necessary to correctly predict the smoking tendency of laminar diffusion flames. ${ }^{61}$ Kennedy et al. ${ }^{62}$ developed a functional form for $\gamma_{\mathrm{OH}-\mathrm{ox}}$ as a function of a nondimensional nozzle distance. In this work the findings of Haudiquert et al..$^{59}$ and Liu et al. ${ }^{60}$ are combined and $\gamma_{\mathrm{OH}-\mathrm{ox}}$ is modelled similar to Eq. 36 by:

$$
\gamma_{\mathrm{OH-ox}}(T)=\left(\frac{1800 K}{T}\right)^{70} \exp \left\{70\left(1-\frac{1800 K}{T}\right)\right\}
$$

\section{Laminar Flames}

A frequently chosen test case for the validation of soot models and in particular soot oxidation models are the laminar atmospheric ethylene diffusion flames of Santoro et al. ${ }^{61}$ These flames are stabilized on a burner with an an $11.1 \mathrm{~mm}$ inner diameter fuel nozzle surrounded by a $101.6 \mathrm{~mm}$ outer air passage. The flames are confined by a $405 \mathrm{~mm}$ brass cylinder. In this set of flames, a variation of fuel and coflow mass flow rates was performed (see table 2) to obtain a transition from a non-smoking flame (Flame 2) to a smoking flame (Flame 4). The inflow conditions of flames 2 and 4 are summarized in table 2. The flames are target flames of the international sooting flame (ISF) workshop (ISF-3 Co-flow 1) and they have been investigated in numerous experimental ${ }^{61,63,62}$ and numerical studies ${ }^{60,22,64}$ (this list of references and the following discussion are considered to be a brief overview and might hence be incomprehensive). Santoro et al. ${ }^{61}$ performed scattering and extinction measurements of soot volume fractions and in a later work, ${ }^{63}$ thermocouple measurements of the temperature. Mole fractions of $\mathrm{C}_{2} \mathrm{H}_{2}$ and $\mathrm{OH}$ have been measured in flame 2 by Kennedy et al. ${ }^{62}$ using MS/GC and LIF. Megarids and Dobbins ${ }^{65}$ obtained primary particle diameters and number densities by electron microscop analysis of sampled soot aggregates. Further experimental studies of the soot morphology were reported in later works by Puri et al. ${ }^{66}$ Köylü et al., ${ }^{67}$ and Iyer et al. ${ }^{68}$

For the validation of soot models, it is important that temperatures, soot precursor species, and soot oxidants are accurately predicted. To this end, Fig. 3 shows predicted and measured ${ }^{62}$ radial profiles of $\mathrm{OH}$ and $\mathrm{C}_{2} \mathrm{H}_{2}$ mole fractions in flame 2. Overall, the agreement between simulation and experiment is excellent. A comparison of measured ${ }^{63}$ and predicted temperatures is shown in Fig. 4. Notable differences between simulation and experiment are found only at the most upstream position close to the flame axis. In the other regions, the agreement between simulation and experiment is very good.

Predicted and measured ${ }^{61}$ profiles of the soot volume fraction $f_{v}$ along the streakline exhibiting the maximum $f_{v}$ are shown in Fig. 5. Using an aggregation factor $\chi_{\text {agg }}=1.5$, the model developed in the present work agrees well to the measurements in both flames. In particular the transition from the non-smoking (flame 2) to the smoking regime (flame 4) where significant amounts soot are not oxidized is predicted. The assumption of spherical soot particles $\left(\chi_{\text {agg }}=1.0\right)$ leads to a smaller soot surface and consequently lower soot surface growth and oxidation rates. This yields as shown in Fig. 5 an underprediction of the peak 

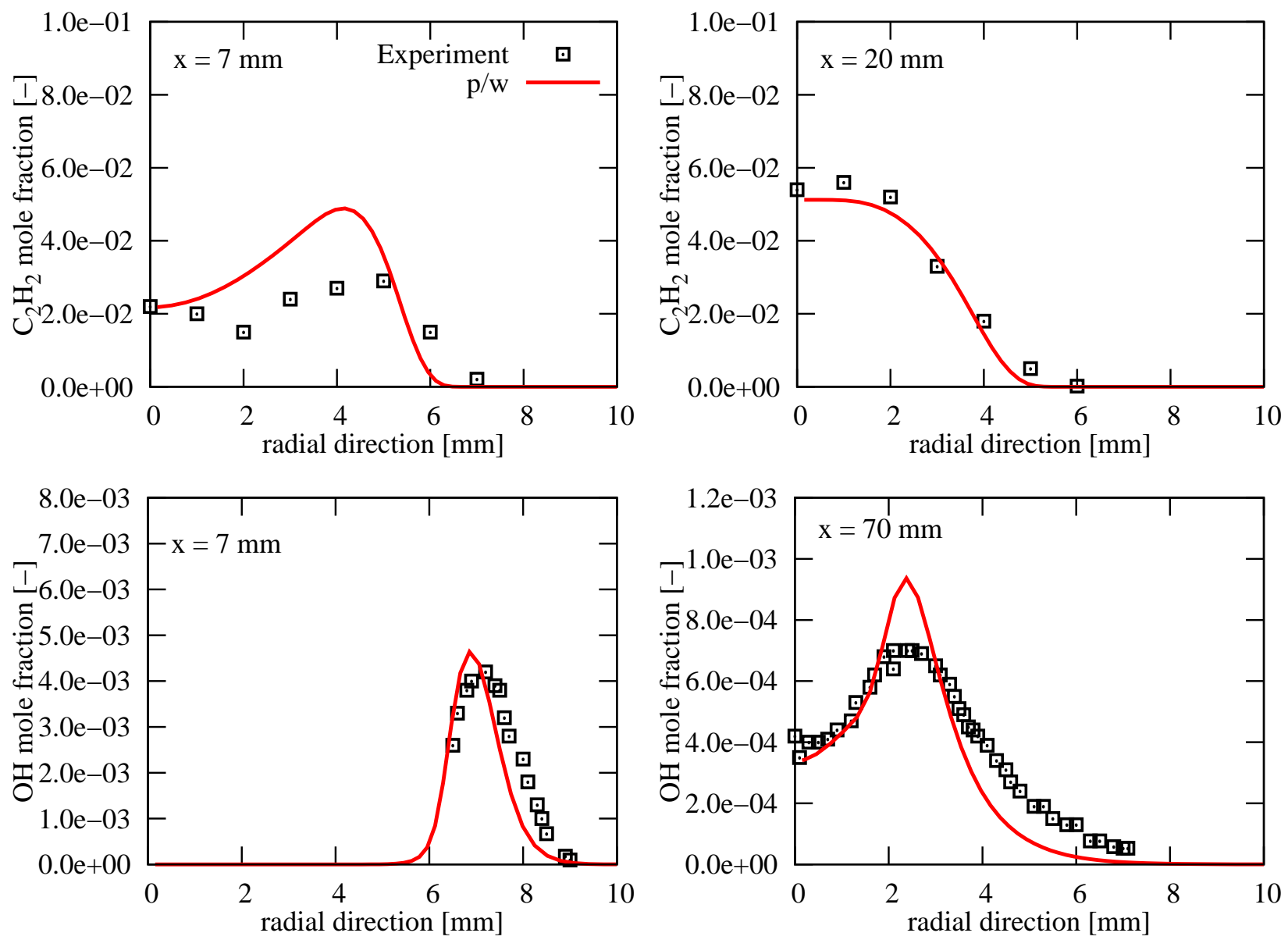

Figure 3. Radial profiles of predicted and measured ${ }^{62} \mathrm{C}_{2} \mathrm{H}_{2}$ and $\mathrm{OH}$ mole fractions in a laminar diffusion flame of ethylene ${ }^{61}$ at different heights above the burner.

Table 3. Boundary conditions of the laminar atmospheric partially premixed flames considered in this work

\begin{tabular}{cccccc}
\hline$\phi$ & $Y_{\mathrm{C}_{2} \mathrm{H}_{4}}$ & $Y_{\mathrm{N}_{2}}$ & $Y_{\mathrm{O}_{2}}$ & $u_{\text {jet }}$ & $u_{\text {co-flow }}$ \\
\hline$\infty$ & 1.0 & 0.0 & 0.0 & $3.98 \mathrm{~cm} / \mathrm{s}$ & $8.9 \mathrm{~cm} / \mathrm{s}$ \\
10 & 0.405 & 0.456 & 0.139 & $9.58 \mathrm{~cm} / \mathrm{s}$ & $8.9 \mathrm{~cm} / \mathrm{s}$ \\
5 & 0.254 & 0.572 & 0.174 & $15.7 \mathrm{~cm} / \mathrm{s}$ & $8.9 \mathrm{~cm} / \mathrm{s}$ \\
\hline
\end{tabular}

soot volume fraction in both flames. Also, both flames are smoking in this case because oxidation rates are too low. With $\chi_{\text {agg }}=2.0$ on the other hand, the soot surface and consequently the soot growth and oxidation rates are very high. The soot volume fraction is thus significantly overpredicted and both flames are non-smoking. The comparison of predicted and measured mean primary particle diameters $d_{p}$, particle number densities and number of particles per aggregate in Figs. 6 and 7 shows a consistent pattern. The assumption of spherical soot particles leads too few particles with too large diameters, while the opposite is true for $\chi_{\text {agg }}=2.0$. With $\chi_{\text {agg }}=1.5$ however, the soot morphology is accurately predicted.

The influence of partial pre-mixing on soot distributions was investigated by Arana et al. ${ }^{69}$ who performed measurements of soot volume fractions and temperatures in partially premixed flames. The flames were operated on the Santoro burner ${ }^{61}$ and the premixing ratio has been varied between $\phi=\infty$ (non-premixed) and $\phi=5$, where the $\phi=\infty$ case corresponds to Santoro's flame 2. Inflow conditions of these atmospheric ethylene flames, which are considered ISF target flames (ISF3 Co-Flow 2), are given in table 3. Axial profiles of measured and predicted temperatures and radially integrated soot volume fractions are shown in Fig. 8. The agreement between simulation and experiment is very good and the model predicts the influence of $\phi$ on temperature and soot distributions correctly. 

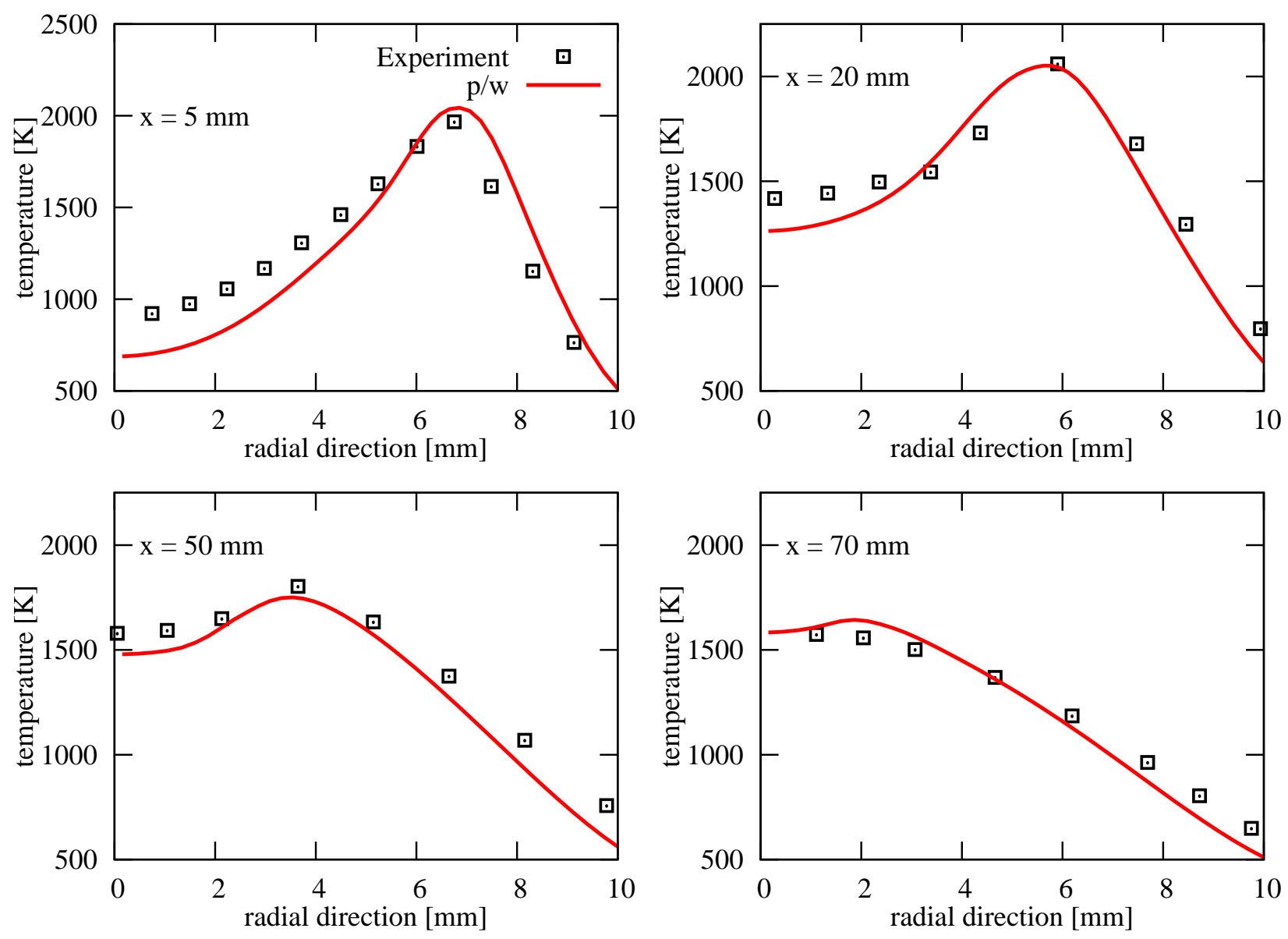

Figure 4. Predicted and measured ${ }^{63}$ temperatures in a laminar diffusion flame of ethylene ${ }^{61}$ at different heights above the burner.

\section{Turbulent Sooting Jet Flame}

\section{IV.A. Test Case Description}

The turbulent ethylene flame addressed in the present work has been investigated experimentally by Köhler et al. ${ }^{14,15,13}$ and is a target flame of the International Sooting Flame (ISF) workshop. The burner consists of a nozzle with an inner diameter of $2 \mathrm{~mm}$. Co-annular dry air flows through a convergent outer nozzle. The bulk jet velocity is $44 \mathrm{~m} / \mathrm{s}$ yielding a nozzle diameter based Reynolds number of 10000 . The co-flow velocity is $0.29 \mathrm{~m} / \mathrm{s}$. The lift-off height amounts to $26 \mathrm{~mm}$ and the visible flame length to $400-500 \mathrm{~mm}$. Comprehensive validation data is available, including temperature measurements by CARS and qualitative measurements of $\mathrm{OH}$ and PAHs using LIF. The mixing in the pre-flame region was characterized by Raman scattering. Velocities and soot volume fractions were measured by simultaneous high-speed PIV and LII.

\section{IV.B. Numerical Setup}

The simulations have been performed with the DLR in-house code THETA. THETA is a parallelized, unstructured finite-volume solver for gas turbine related combustion problems. Pressure velocity coupling is realized by a projection method. ${ }^{70,71}$ Second order accurate discretization schemes are applied in space and time. The three-dimensional computational domain is discretized by 3.4 million hexahedral volumes. The time step width amounts to $0.5 \mu$ s and the physical sampling time to approximately $88 \mathrm{~ms}$. The simulation has been executed on 560 cores (Sandy Bridge-EP Xeon E5-2680 8C processors) in parallel requiring a total of $6 \times 10^{5}$ core hours.

For LES, an unsteady velocity distribution which features the statistics and spatio-temporal correlations of a turbulent flow is required as inflow condition. This velocity signal has been obtained by a wall-resolving 

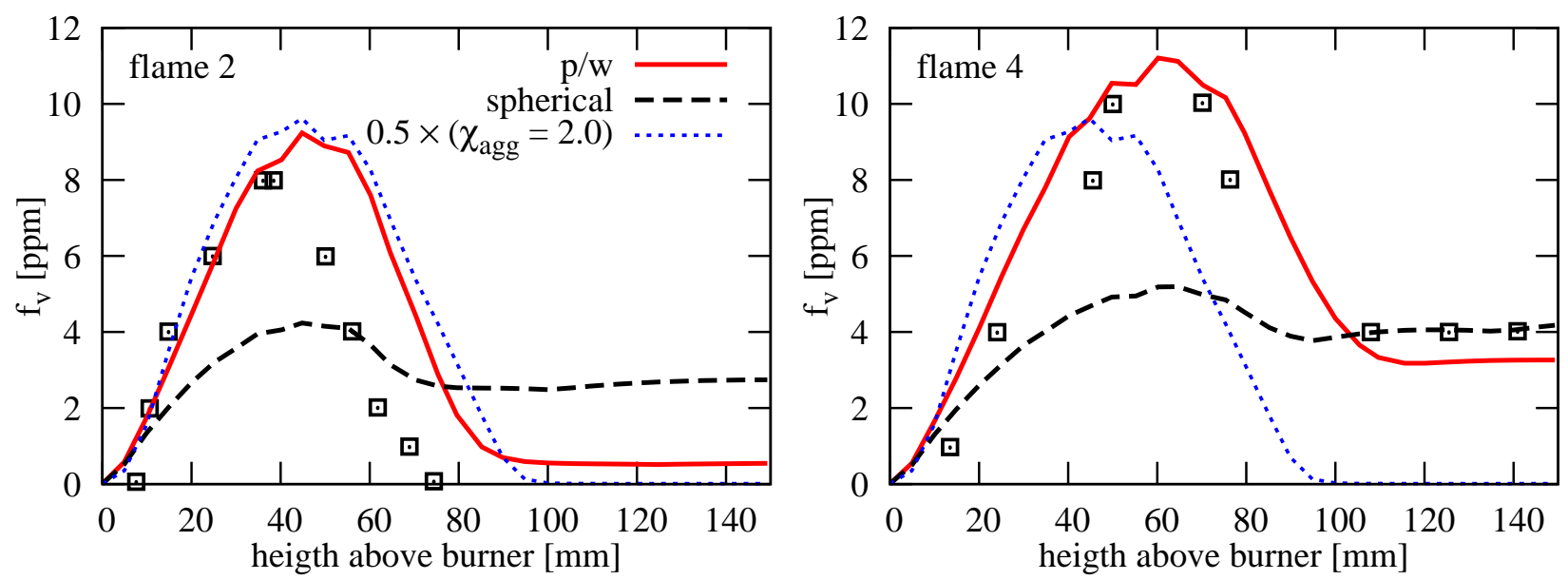

Figure 5. Predicted and measured ${ }^{61}$ profiles of the soot volume fraction $f_{v}$ along the streakline exhibiting the maximum $f_{v}$.
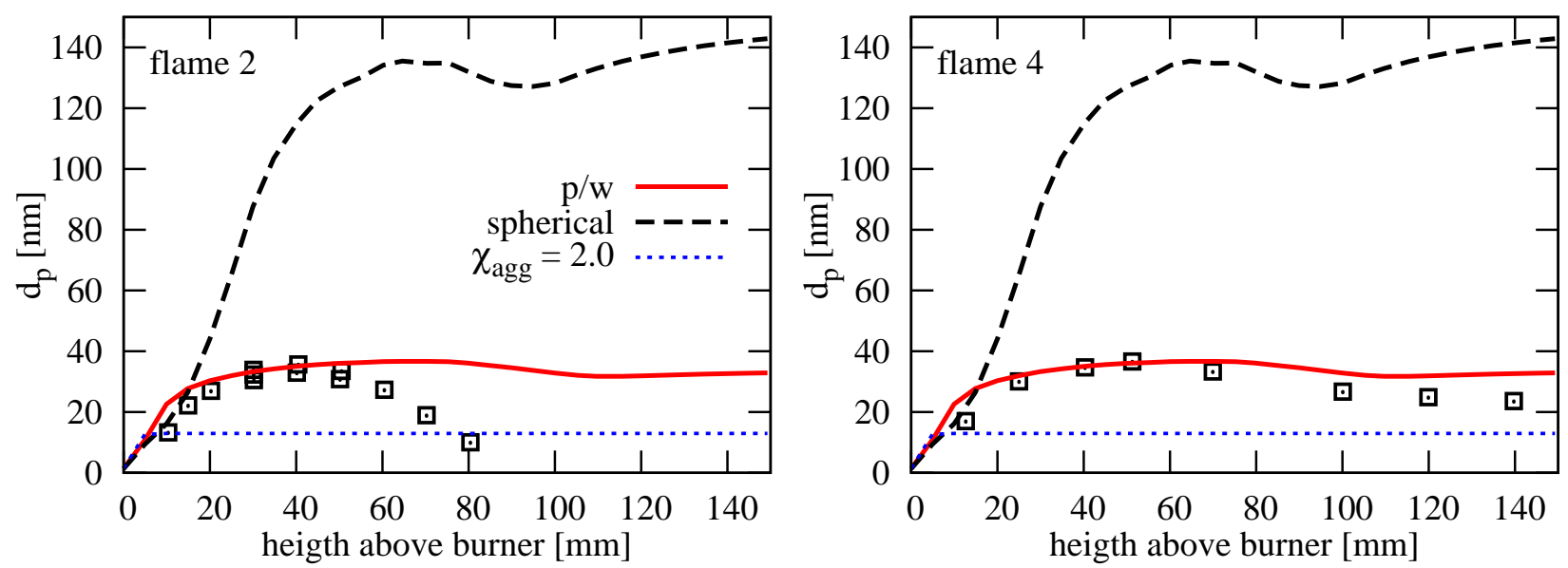

Figure 6. Predicted and measured ${ }^{65}$ profiles of the mean primary particle diameter along the streakline exhibiting the maximum $f_{v}$.

LES of a periodic pipe flow. A very fine grid with 11 million volumes was used yielding a wall resolution $y^{+}<$ 1.0 and a almost uniform grid spacing. The pressure difference in axial direction has been calculated using a correlation for fully-developed, turbulent pipe flow. ${ }^{72}$ Radial profiles of the mean axial velocity are given in Fig. 9 showing an excellent agreement between LES and DNS results from Eggels et al. ${ }^{73}$ Time-resolved velocity data was extracted from this pipe flow LES and used as unsteady inflow condition of the turbulent flame simulation.

\section{IV.C. Instantaneous Flame Structure}

Figure 10 shows representative, instantaneous LES results. The axial velocity distribution reveals a high disparity of turbulent time scales which results from the interaction of the high-velocity fuel jet with the slow co-flowing air. This is particularly challenging for time resolved simulations, since small time steps are required for reasons of accuracy and numerical stability and on the other hand long simulation times are needed to obtain converged statistics. The shape of the wrinkled flame front, which is indicated by the $\mathrm{OH}$ mass fraction, compares well to measurements. ${ }^{13}$ In agreement to the experimental data from Köhler et al., ${ }^{13}$ soot formation starts in fuel rich regions at about $50 \mathrm{~mm}$ above the burner. The soot structures are enveloped by the wrinkled flame front and overlapping between soot and $\mathrm{OH}$ is minor due to the high oxidative potential of $\mathrm{OH}$. 

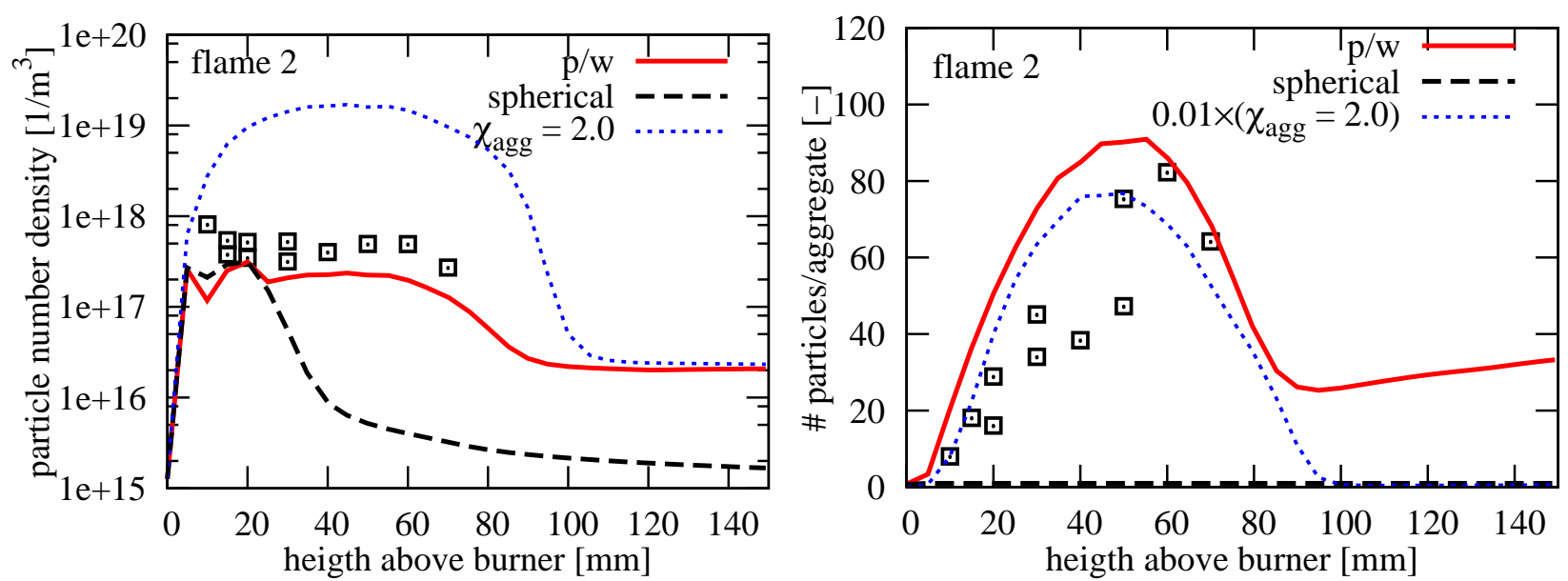

Figure 7. Predicted and measured $61,66,67,68$ profiles of the particle number density and the number of particles per aggregate along the streakline exhibiting the maximum $f_{v}$.
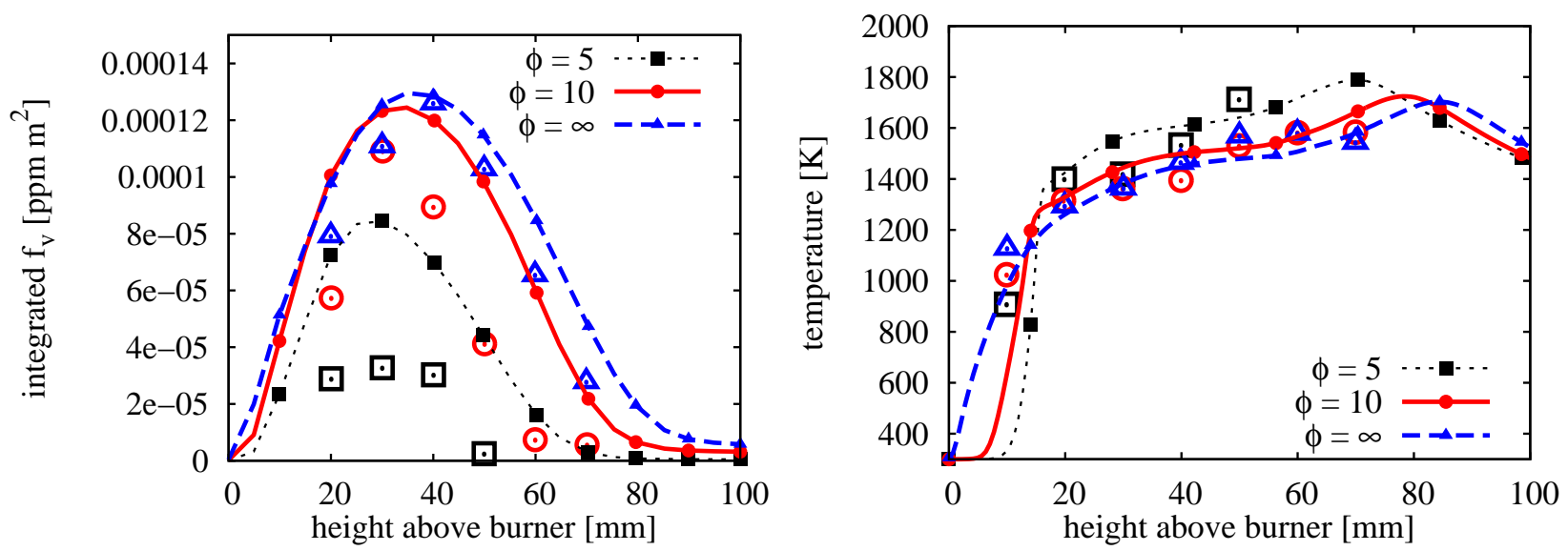

Figure 8. Axial profiles of predicted and measured ${ }^{69}$ soot volume fractions (left panel) and temperatures (right panes) in a laminar partially premixes flames at different equivalence ratios.

\section{IV.D. Flame Statistics}

Figure 11 shows a comparison of predicted and measured ethylene mole fractions in the pre-flame region. Time-averages are shown on the left and rms values on the right. Excellent agreement between simulation and experiment is observed at all axial positions shown. Note that ethylene measurements could not be conducted within the flame. ${ }^{13}$ Figure 12 shows radial profiles of predicted and measured ${ }^{13}$ axial velocities. At the axial position $\mathrm{x}=30 \mathrm{~mm}$, the agreement between simulation and experiment is very good. Further downstream the LES shows a higher jet spreading rate than the experiment. At the most downstream position, LES and experiment are in good agreement. Axial profiles of mean and rms temperatures are shown in Fig. 13. The simulation results show some scatter at $x>300 \mathrm{~mm}$. This is due to unsteady motions which occur at very large time and length scales. In this region, significantly more sampling time would be required to obtain fully converged statistics. This is beyond the scope of this paper, however. Nevertheless, a very good agreement between simulation and experiment is observed. This applies also for the radial profiles shown in Fig. 14. Further temperature measurements which resolve the rms peaks in regions of high temperature gradients would be most welcome.

\section{IV.E. Distribution of Soot and PAHs}

Figure 15 shows predicted and measured axial profiles of of $\mathrm{PAH}_{1}$ mass fractions and soot volume fractions. Note that the experimental PAH data is qualitative and was scaled to match the maximum calculated $\mathrm{PAH}_{1}$ mass fraction. The LES predicts $\mathrm{PAH}_{1}$ to peak earlier than the experiment. The agreement is however 


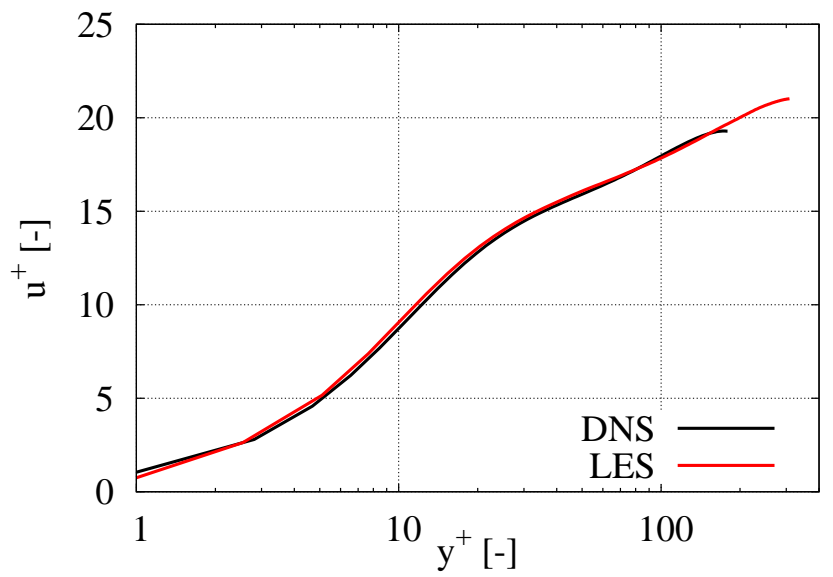

Figure 9. Radial profiles of the calculated mean axial velocity in wall units. The DNS data is taken from Eggels et al. ${ }^{73}$.

considered good given the high complexity. An excellent agreement of predicted and measured $f_{v}$ profiles is observed. A comparison of simulation and experiment in terms of radial $f_{v}$ profiles is shown 16 . At the most upstream position, the simulation shows some asymmetrie. This is, as discussed above, because the statistics are not fully converged. The measured profiles appear to be somewhat wider than the predicted ones. Regarding the peak soot volume fractions, simulation and experiment agree very well at all positions shown.

\section{Conclusion}

A novel sectional soot model has been developed and coupled to a recently published PAH model. The soot model considers the formation of fractal soot aggregates using an efficient uni-sectional approach. Excellent agreement to experimental data has been obtained in a series of laminar non-premixed and partially premixed flames. The formation of fractal soot aggregates and the corresponding change of soot surface area have been found to strongly influence the smoking behaviour of these flames. The results indicate that fractal aggregates are required to correctly predict the soot morphology at heavily sooting combustion conditions. The validated soot model was then used for large eddy simulations of a turbulent sooting jet flame. Overall, a very good agreement to measurements was observed. In particular, measured and predicted soot volume fractions agree very well. A more detailed evaluation of LES results is envisaged in future works.

\section{Acknowledgments}

The authors thank G. Eckel, Dr. A. Fiolitakis, F. Hempert, and A. Steinbach for their contribution to this work. The authors gratefully acknowledge the Gauss Centre for Supercomputing e.V. (www.gausscentre.eu) for funding this project by providing computing time on the GCS Supercomputer SuperMUC at Leibniz Supercomputing Centre (LRZ, www.lrz.de). 


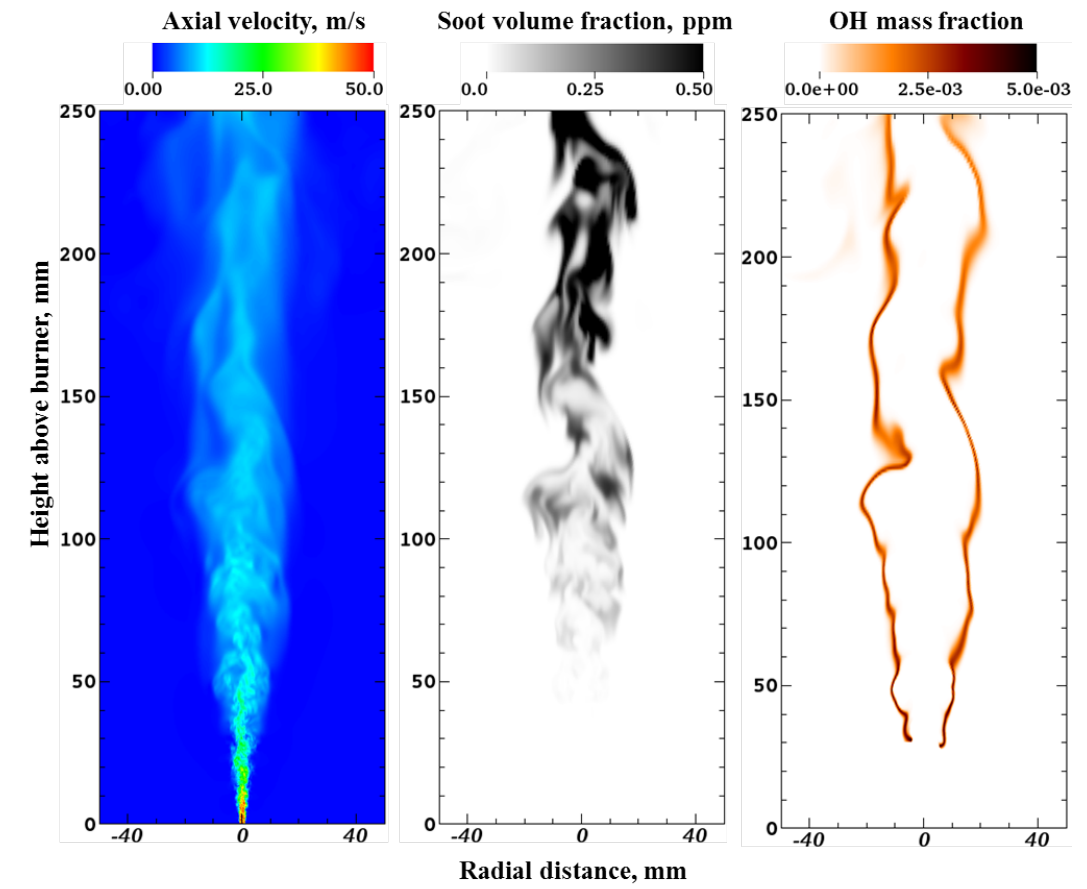

Figure 10. Instantaneous LES results for axial velocity, soot volume fraction, and OH mass fraction 

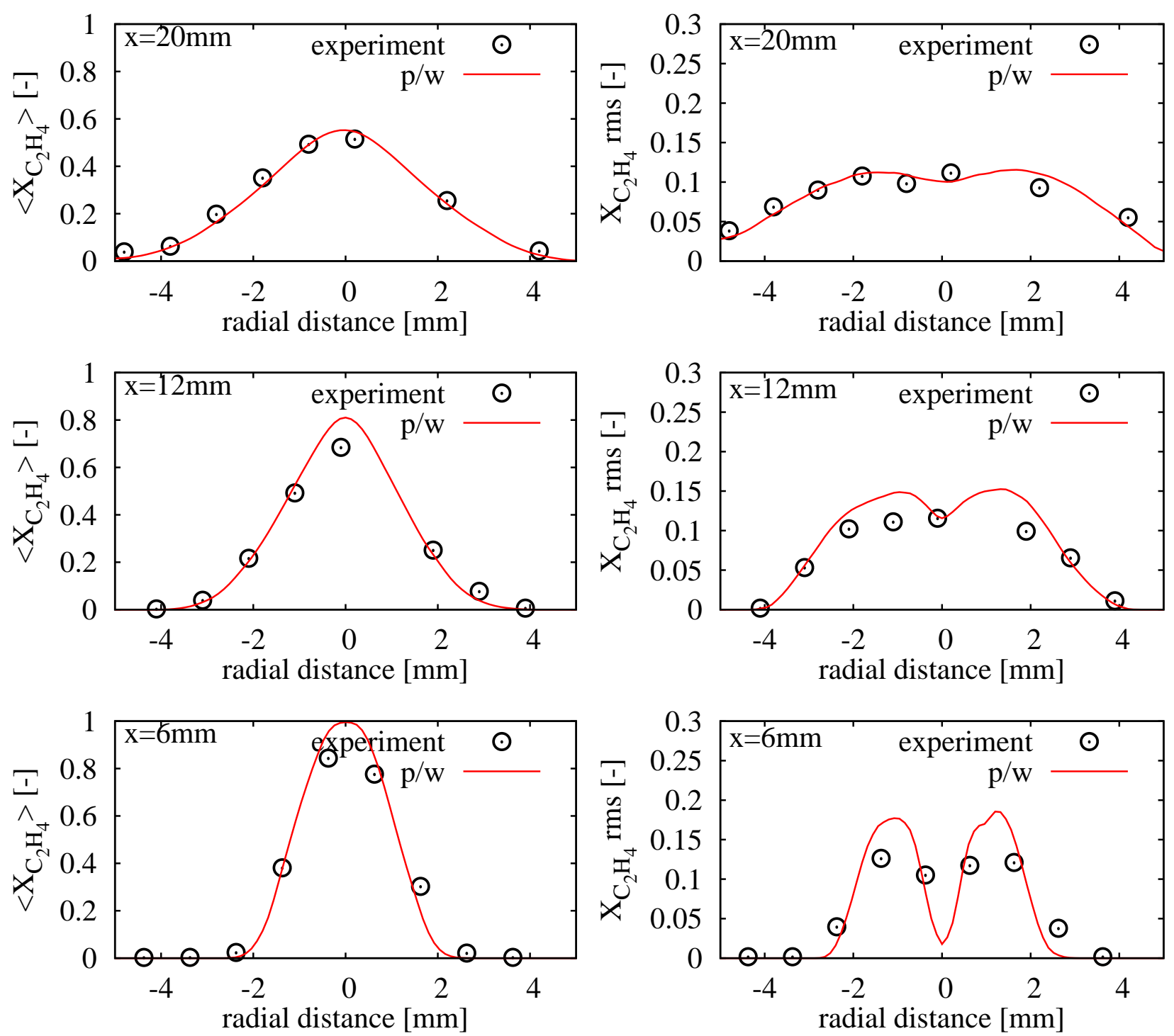

Figure 11. Radial profiles of time-averaged (left column) and rms (right column) ethylene mole fractions at selected downstream positions. Lines are LES results and points measurements from Köhler et al. ${ }^{13}$ 

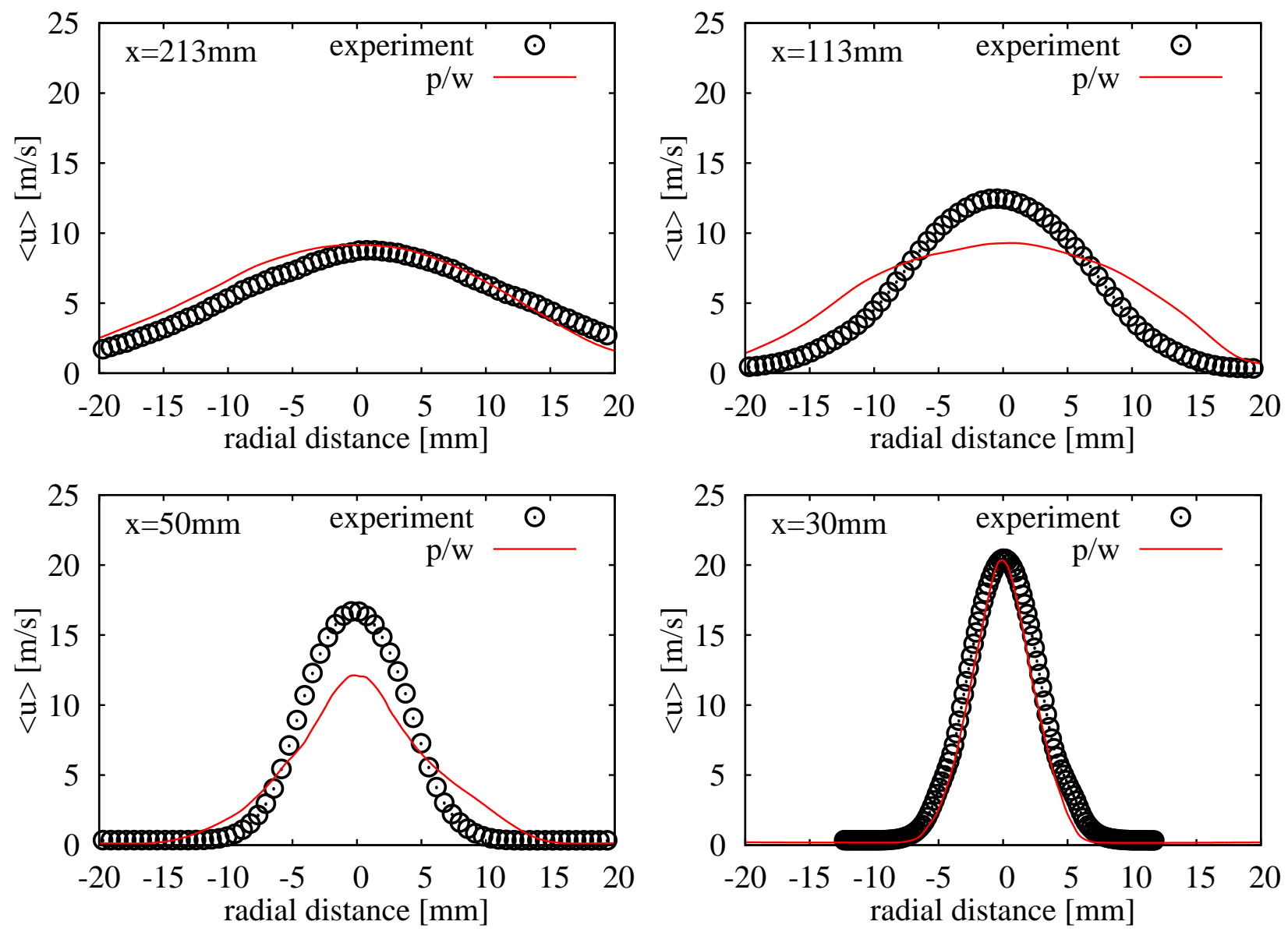

Figure 12. Radial profiles of time-averaged axial velocities at selected downstream positions. Lines are LES results and points measurements from Köhler et al. ${ }^{13}$
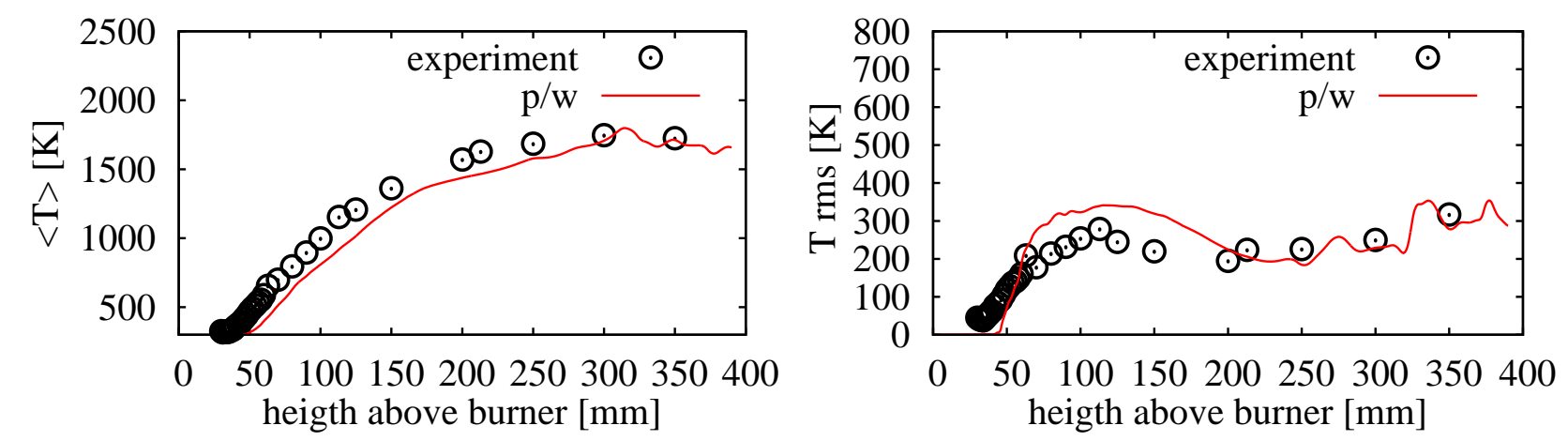

Figure 13. Axial profiles of time-averaged (left column) and rms (right column) temperatures. Lines are LES results and points measurements from Köhler et al. ${ }^{13}$ 

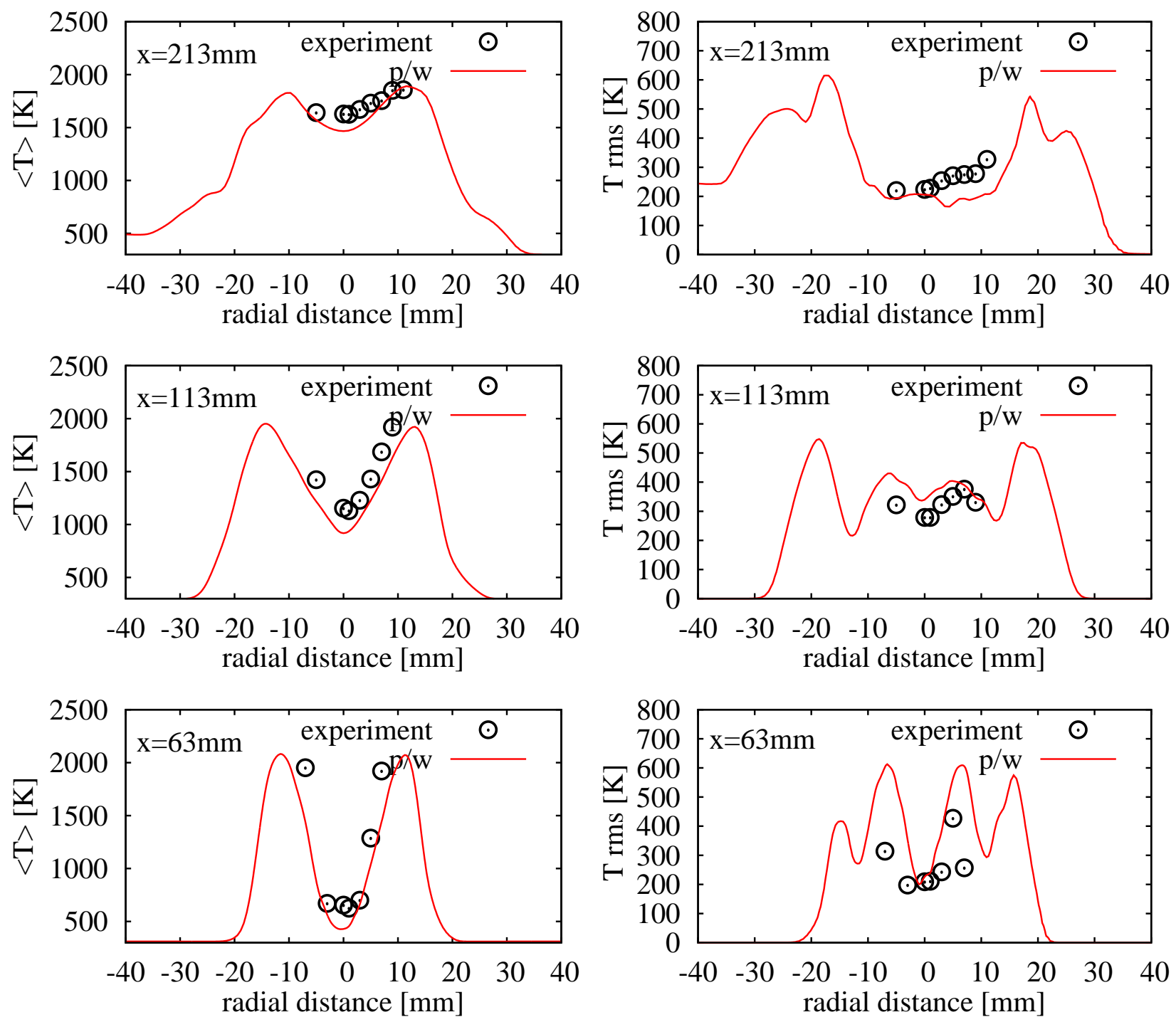

Figure 14. Radial profiles of time-averaged (left column) and rms (right column) temperatures at selected downstream positions. Lines are LES results and points measurements from Köhler et al. ${ }^{1}$
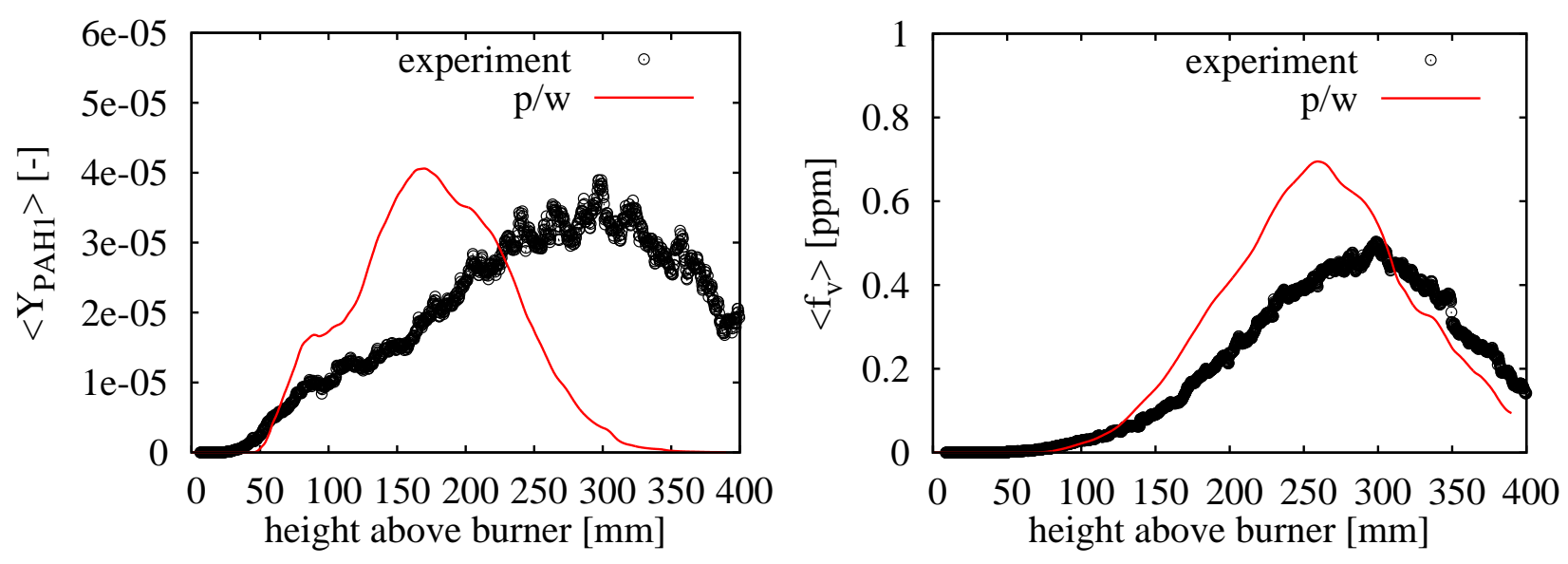

Figure 15. Axial profiles of time-averaged $\mathrm{PAH}_{1}$ mass fractions (left plot) and soot volume fractions (right plot). Lines are LES results and points measurements from Köhler et al. ${ }^{13}$ The $\mathbf{P A H}_{1}$ experimental data is qualitative and was scaled to match the maximum calculated $\mathrm{PAH}_{1}$ mass fraction. 

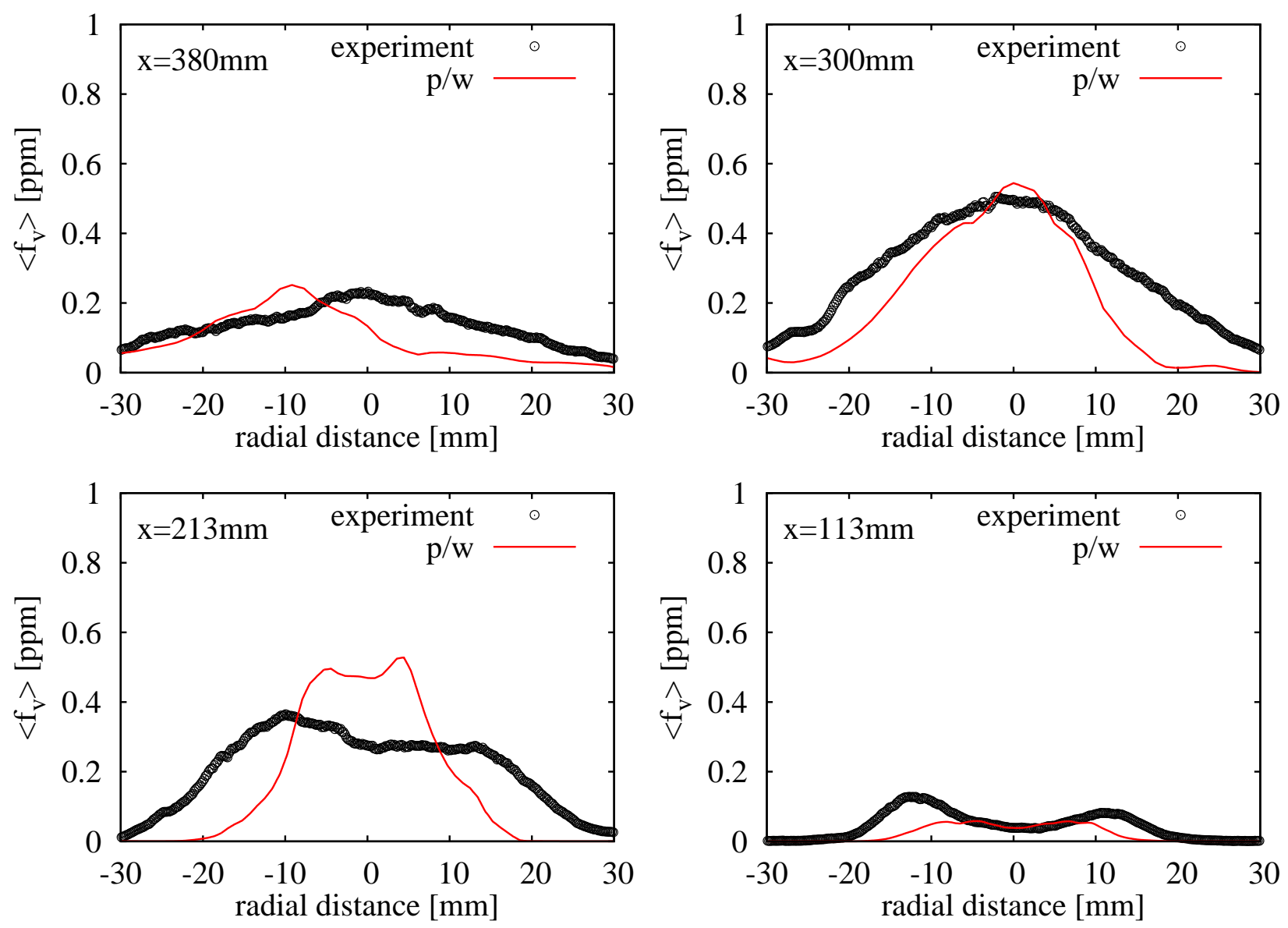

Figure 16. Radial profiles of time-averaged soot volume fractions at selected downstream positions. Lines are LES results and points measurements from Köhler et al. ${ }^{13}$ 


\section{References}

${ }^{1}$ Barfknecht, T. R., "Toxicology of soot," Progress in Energy and Combustion Science, Vol. 9, 1983, pp. $199-237$.

${ }^{2}$ Chrisp, C. E. and Fisher, G. L., "Mutagenicity of airborne particles," Mutation Research/Reviews in Genetic Toxicology, Vol. 76, 1980, pp. 143-164.

${ }^{3}$ Dasenbrock, C., Peters, L., Creutzenberg, O., and Heinrich, U., "The carcinogenic potency of carbon particles with and without PAH after repeated intratracheal administration in the rat," Toxicology Letters, Vol. 88, 1996, pp. 15-21.

${ }^{4}$ Jensen, E. J. and Toon, O. B., "The potential impact of soot particles from aircraft exhaust on cirrus clouds," Geophysical Research Letters, Vol. 24, 1997, pp. 249-252.

${ }^{5}$ Petzold, A., Ström, J., Ohlsson, S., and Schröder, F. P., "Elemental composition and morphology of ice-crystal residual particles in cirrus clouds and contrails," Atmospheric Research, Vol. 49, 1998, pp. 21-34.

${ }^{6}$ Petzold, A., Ström, J., Schröder, F. P., and Kärcher, B., "Carbonaceous aerosol in jet engine exhaust: emission characteristics and implications for heterogeneous chemical reactions," Atmospheric Environment, Vol. 33, 1999, pp. 2689-2698.

${ }^{7}$ Lee, C. K., "Estimates of luminous flame radiation from fires," Combustion and Flame, Vol. 24, 1975, pp. $239-244$.

${ }^{8}$ Lefebvre, A. H., "Radiation from flames in gas turbines and rocket engines," Proceedings of the Combustion Institute, Vol. 12, 1969, pp. 1247-1253.

${ }^{9}$ Nakamura, M., Koda, S., and Akita, K., "Sooting behavior and radiation in methanol/benzene/air diffusion flames," Proceedings of the Combustion Institute, Vol. 19, 1982, pp. 1395-1401.

${ }^{10}$ Mueller, M. E. and Pitsch, H., "LES model for sooting turbulent nonpremixed flames," Combustion and Flame, Vol. 159, 2012, pp. 2166-2180.

${ }^{11}$ Donde, P., Raman, V., Mueller, M. E., and Pitsch, H., "LES/PDF based modeling of soot-turbulence interactions in turbulent flames," Proceedings of the Combustion Institute, Vol. 34, 2013, pp. 1183-1192.

${ }^{12}$ Mueller, M., Chan, Q., Qamar, N., Dally, B., Pitsch, H., Alwahabi, Z., and Nathan, G., "Experimental and computational study of soot evolution in a turbulent nonpremixed bluff body ethylene flame," Combustion and Flame, Vol. 160, 2013, pp. 12981309.

${ }^{13}$ Köhler, M., Geigle, K. P., Blacha, T., Gerlinger, P., and Meier, W., "Experimental characterization and numerical simulation of a sooting lifted turbulent jet diffusion flame," Combustion and Flame, Vol. 159, 2012, pp. 2620-2635.

${ }^{14}$ Köhler, M., Boxx, I., Geigle, K. P., and Meier, W., "Simultaneous planar measurements of soot structure and velocity," Applied Physics B, Vol. 103, 2011, pp. 271-279.

${ }^{15}$ Köhler, M., Geigle, K. P., Meier, W., Crosland, B. M., Thomson, K. A., and Smallwood, G. J., "Sooting turbulent jet flame: characterization and quantitative soot measurements," Applied Physics B, Vol. 104, 2011, pp. 409-425.

${ }^{16}$ Blacha, T., Di Domenico, M., Köhler, M., Gerlinger, P., and Aigner, M., "Soot modeling in a turbulent unconfined $\mathrm{C}_{2} \mathrm{H}_{4}$ /air jet flame," Proceedings of the 49th AIAA Aerospace Science Meeting, No. AIAA 2011-0114, 2011.

${ }^{17}$ Eberle, C., Gerlinger, P., and Aigner, M., "A sectional PAH model with reversible PAH chemistry for CFD soot simulations," Submitted to Combustion and Flame, 2016.

${ }^{18}$ Nicoud, F. and Ducros, F., "Subgrid-scale stress modelling based on the square of the velocity gradient tensor," Flow, Turbulence and Combustion, Vol. 62, 1999, pp. 183-200.

${ }^{19}$ Mauss, F., Entwicklung eines kinetischen Modells der Rußbildung mit schneller Polymerisation, Ph.D. thesis, RheinischWestfälische Technische Hochschule Aachen, 1998.

${ }^{20}$ Mueller, M. E. and Pitsch, H., "Large eddy simulation subfilter modeling of soot-turbulence interactions," Physics of Fluids, Vol. 23, 2011, pp. 115104.

${ }^{21}$ Di Domenico, M., Gerlinger, P., and Aigner, M., "Development and validation of a new soot formation model for gas turbine combustor simulations," Combustion and Flame, Vol. 157, 2010, pp. 246-258.

${ }^{22}$ Blacha, T., Di Domenico, M., Gerlinger, P., and Aigner, M., "Soot predictions in premixed and non-premixed laminar flames using a sectional approach for PAHs and soot," Combustion and Flame, Vol. 159, 2012, pp. 181-193.

${ }^{23}$ Girimaji, S. S., "Assumed $\beta$-pdf model for turbulent mixing: validation and extension to multiple scalar mixing," Combustion Science and Technology, Vol. 78, 1991, pp. 177-196.

${ }^{24}$ Gerlinger, P., "Investigation of an assumed PDF approach for finite-rate chemistry," Combustion Science and Technology, Vol. 175, 2003, pp. 841-872.

${ }^{25}$ Di Domenico, M., Numerical simulations of soot formation in turbulent flows, Ph.D. thesis, Institute of Combustion Technology for Aerospace Engineering Universität Stuttgart, 2008.

${ }^{26}$ Di Domenico, M., Gerlinger, P., and Noll, B., "Numerical simulations of confined turbulent lean premixed flames using a detailed chemistry combustion model," Proceedings of the ASME Turbo Expo 2011: Power for Land, Sea and Air, No. GT2011-45520, 2011.

${ }^{27}$ Ivanova, E., Noll, B., Griebel, P., Aigner, M., and Syed, K., "Numerical simulations of turbulent mixing and autoignition of hydrogen fuel at reheat combustor operating conditions," Journal of Engineering for Gas Turbines and Power, Vol. 134, 2012, pp. 041504-01-041504-07.

${ }^{28}$ Lourier, M., Eberle, C., Noll, B., and Aigner, M., "Influence of turbulence-chemistry interaction modeling on the structure and the stability of a swirl-stabilized flame," Proceedings of the ASME Turbo Expo 2015: Power for Land, Sea and Air, No. GT2015-43174, 2015.

${ }^{29}$ Eberle, C., Gerlinger, P., Geigle, K. P., and Aigner, M., "Numerical investigation of transient soot evolution processes in an aero-engine model combustor," Combustion Science and Technology, Vol. 187, 2015, pp. 1841-1866.

${ }^{30}$ Eberle, C., Gerlinger, P., and Aigner, M., "A comparison of URANS and LES for soot predictions in an aero-engine model combustor," Deutscher Luft- und Raumfahrtkongress 2015, 22.09.-24.09.2015, Rostock, Deutschland, submitted to CEAS Aeronautical Journal, 2015.

${ }^{31}$ Slavinskaya, N. A. and Haidn, O. J., "Reduced chemical model for high pressure methane combustion with PAH formation," Proceedings of the 46th AIAA Aerospace Sciences Meeting, No. AIAA 2008-1012, 2008. 
${ }^{32}$ Slavinskaya, N. A. and Frank, P., "A modelling study of aromatic soot precursors formation in laminar methane and ethene flames," Combustion and Flame, Vol. 156, 2009, pp. 1705-1722.

${ }^{33}$ Abid, A. D., Tolmachiff, E. D., Phares, D. J., Wang, H., Liu, Y., and Laskin, A., "Size distribution and morphology of nascant soot in premixed ethylene flames with and without benzene doping," Proceedings of the Combustion Institute, Vol. 32, 2009, pp. 681-688.

${ }^{34}$ Slavinskaya, N. A., Riedel, U., Dworkin, S. B., and Thomson, M. J., "Detailed numerical modeling of PAH formation and growth in non-premixed ethylene and ethane flames," Combustion and Flame, Vol. 159, 2012, pp. 979-995.

${ }^{35}$ Frenklach, M. and Wang, H., "Detailed mechanism and modeling of soot particle formation," Soot Formation in Combustion, edited by H. Bockhorn, Springer Verlag, 1994.

${ }^{36}$ Pope, C. J. and Howard, J. B., "Simultaneous particle and molecule modeling (SPAMM): An approach for combining sectional aerosol equations and elementary gas-phase reactions," Aerosol Science and Technology, Vol. 27, 1997, pp. 73-94.

${ }^{37}$ Fuchs, N. A., The Mechanics of Aerosols, Pergamon Press, Oxford, 1964.

${ }^{38}$ D'Alessio, A., Barone, A. C., Cau, R., D'Anna, A., and Minutolo, P., "Surface deposition and coagulation efficiency of combustion generated nanoparticles in the size range from 1 to $10 \mathrm{~nm}$," Proceedings of the Combustion Institute, Vol. 30, 2005, pp. 2595-2603.

${ }^{39}$ Saggese, C., Ferrario, S., Camacho, J., Cuoci, A., Frassoldati, A., Ranzi, E., Wang, H., and Faravelli, T., "Kinetic modeling of particle size distribution of soot in a premixed burner-stabilized stagnation ethylene flame," Combustion and Flame, Vol. 162, 2015, pp. 3356-3369.

${ }^{40}$ Richter, H., Granata, S., Green, W. H., and Howard, J. B., "Detailed modeling of PAH and soot formation in a laminar premixed benzene/oxygen/argon low-pressure flame," Proceedings of the Combustion Institute, Vol. 30, 2005, pp. 1397-1405.

${ }^{41}$ D'Anna, A., Sirignano, M., and Kent, J., "A model of particle nucleation in premixed ethylene flames," Combustion and Flame, Vol. 157, 2010, pp. 2106-2115.

${ }^{42}$ D'Anna, A. and Kent, J. H., "A model of particulate and species formation applied to laminar, nonpremixed flames for three aliphatic-hydrocarbon fuels," Combustion and Flame, Vol. 152, 2008, pp. 573-587.

${ }^{43}$ Donnet, J. B., Bansal, R. C., and Wang, M. J., editors, Carbon black, Marcel Dekker Inc, 1993.

${ }^{44}$ Gelbard, F. and Seinfeld, J. H., "Simulation of multicomponent aerosol dynamics," Journal of Colloid and Interface Science, Vol. 78, 1980, pp. 485-501.

${ }^{45}$ Kazakov, A. and Frenklach, M., "Dynamic modeling of soot particle coagulation and aggregation: implementation with the method of moments and application to high-pressure laminar premixed flames," Combustion and Flame, Vol. 114, 1998, pp. $484-501$.

${ }^{46}$ Bhatt, J. S. and Lindstedt, R. P., "Analysis of the impact of agglomeration and surface chemistry models on soot formation and oxidation," Proceedings of the Combustion Institute, Vol. 32, 2009, pp. 713-720.

${ }^{47}$ Smooke, M. D., Long, M. B., Connelly, B. C., Colket, M. B., and Hall, R. J., "Soot formation in laminar diffusion flames," Combustion and Flame, Vol. 143, 2005, pp. 613-628.

${ }^{48}$ Köylü, U. O., Xing, Y., and Rosner, D. E., "Fractal morphology analysis of combustion-generated aggregates using angular light scattering and electron microscope images," Langmuir, Vol. 11, 1995, pp. 4848-4854.

${ }^{49}$ Rosner, D. E. and Pyykönen, J. J., "Bivariate moment simulation of coagulating and sintering nanoparticles in flames," AIChE Journal, Vol. 48, 2002, pp. 476-491.

${ }^{50}$ Appel, J., Bockhorn, H., and Frenklach, M., "Kinetic modeling of soot formation with detailed chemistry and physics: laminar premixed flames of C2 hydrocarbons," Combustion and Flame, Vol. 121, 2000, pp. 122-136.

${ }^{51}$ Frenklach, M. and Wang, H., "Detailed modeling of soot particle nucleation and growth," Proceedings of the Combustion Institute, Vol. 23, 1990, pp. 1559-1556.

${ }^{52}$ Mehta, R. S., Haworth, D. C., and Modest, M. F., "An assessment of gas-phase reaction mechanisms and soot models for laminar atmospheric-pressure eethylene-air flames," Proceedings of the Combustion Institute, Vol. 157, 2009, pp. 982-994.

${ }^{53}$ Wang, H., Du, D. X., Sung, C. J., and Law, C. K., "Experiments and numerical simulation on soot formation in opposedjet ethylene diffusion flames," Proceedings of the Combustion Institute, Vol. 26, 1996, pp. 2359-2368.

${ }^{54}$ Raj, A., da Silva, G. R., and Chung, S. H., "Reaction mechanism for the free-edge oxidation of soot by $\mathrm{O}_{2}$," Combustion and Flame, Vol. 159, 2012, pp. 3423-3436.

${ }^{55}$ Woods, I. T. and Haynes, B. S., "Soot surface growth at active sites," Combustion and Flame, Vol. 85, 1991, pp. 532-525.

${ }^{56}$ Markatou, P., Wang, H., and Frenklach, M., "A computational study of sooting limits in laminar premixed flames of ethane, ethylene, and acetylene," Combustion and Flame, Vol. 93, 1993, pp. 467-682.

${ }^{57}$ Khosousi, A. and Dworkin, S. B., "Detailed modelling of soot oxidation by $\mathrm{O}_{2}$ and $\mathrm{OH}$ in laminar diffusion flames," Proceedings of the Combustion Institute, Vol. 35, 2014, pp. 1903-1910.

${ }^{58}$ Neoh, K. G., Howard, J. B., and Sarofim, A. F., "Soot oxidation in flames," Particulate Carbon, edited by D. Siegla, Springer Verlag, 1981, pp. 261-282.

${ }^{59}$ Haudiquert, M., Cessou, A., Stepowski, D., and Coppalle, A., "OH and soot concentration measurements in a hightemperature laminar diffusion flame," Combustion and Flame, 1997.

${ }^{60}$ Liu, F., Guo, H., Smallwood, G. J., and Gülder, O. L., "Numerical modelling of soot formation and oxidation in laminar coflow non-smoking and smoking ethylene diffusion flames," Combustion Theory and Modelling, Vol. 7, 2003, pp. 301-315.

${ }^{61}$ Santoro, R. J., Semerjian, H. G., and Dobbins, R. A., "Soot particle measurements in diffusion flames," Combustion and Flame, Vol. 51, 1983, pp. 203-218.

${ }^{62}$ Kennedy, I. M., Yam, C., Rapp, D. C., and Santoro, R. J., "Modeling and measurements of soot and species in a laminar diffusion flame," Combustion and Flame, Vol. 107, 1996, pp. 368-382.

${ }^{63}$ Santoro, R. J., Yeh, T. T., Horvath, J. J., and Semerjian, H. G., "The transport and growth of soot particles in laminar diffusion flames," Combustion Science and Technology, Vol. 53, 1987, pp. 89-115. 
${ }^{64}$ Khosousi, A. and Dworkin, S. B., "Soot surface reactivity during surface growth and oxidation in laminar diffusion flames," Combustion and Flame, Vol. 162, 2015, pp. 4523-4532.

${ }^{65}$ Megaridis, C. M. and Dobbins, R. A., "Comparison of soot growth and oxidation in smoking and non-smoking ethylene diffusion flames," Combustion Science and Technology, Vol. 66, 1989, pp. 1-16.

${ }^{66}$ Puri, R., Richardson, T. F., Santoro, R. J., and Dobbins, R. A., "Aerosol dynamic processes of soot aggregates in a laminar ethene diffusion flame," Combustion and Flame, Vol. 92, 1993, pp. 320-333.

${ }^{67}$ Köylü, U. O., McEnally, C., Rosner, D., and Pfefferle, L., "Aerosol dynamic processes of soot aggregates in a laminar ethene diffusion flame," Combustion and Flame, Vol. 110, 1997, pp. 494-507.

${ }^{68}$ Iyer, S. S., Litzinger, T. A., Lee, S. Y., and Santoro, R. J., "Determination of soot scattering coefficient from extinction and three-angle scattering in a laminar diffusion flame," Combustion and Flame, Vol. 140, 2007, pp. $206-216$.

${ }^{69}$ Arana, C. P., Pontoni, M., Sen, S., and Puri, I. K., "Field measurements of soot volume fractions in laminar partially premixed coflow ethylene/air flames," Combustion and Flame, Vol. 138, 2004, pp. 362-372.

${ }^{70}$ Chorin, A. J., "Numerical solution of the Navier-Stokes equations," Mathematics of Computation, Vol. 22, No. 104, 1968, pp. $745-762$.

${ }^{71}$ Chorin, A. J., "On the convergence of discrete approximations to the Navier-Stokes equations," Mathematics of Computation, Vol. 23, No. 106, 1969, pp. 341-353.

${ }^{72}$ Oertel, H. and Prandtl., L., Prandtl-Führer durch die Strömungslehre, Vieweg, 2001.

${ }^{73}$ Eggels, J. G. M., Unger, F., Weiss, M. H., Westerweel, J., Adrian, R. J., Friedrich, R., and Nieuwstadt, F. T. M., "Fully developed turbulent pipe flow: a comparison between direct numerical simulation and experiment," Journal of Fluid Mechanics, Vol. 268, 1994, pp. 175-210. 